\title{
Experimental Development and Evaluation of Pneumatic Powered-Lift Super-STOL Aircraft
}

\author{
Robert J. Englar* \\ Georgia Tech Research Institute (GTRI) \\ Aerospace, Transportation and Advanced Systems Laboratory \\ Atlanta, GA 30332-0844 \\ and \\ Bryan A. Campbell** \\ NASA Langley Research Center (LaRC) \\ Configuration Aerodynamics Branch, MS 286 \\ Hampton, VA 23681-2199
}

\begin{abstract}
The powered-lift Channel Wing concept has been combined with pneumatic Circulation Control aerodynamic and propulsive technology to generate a Pneumatic Channel Wing (PCW) configuration intended to have Super-STOL or VSTOL capability while eliminating many of the operational problem areas of the original Channel Wing vehicle. Wind-tunnel development and evaluations of a PCW powered model conducted at Georgia Tech Research Institute (GTRI) have shown substantial lift capabilities for the blown configuration $\left(C_{L}\right.$ values of 10 to 11$)$. Variation in blowing of the channel was shown to be more efficient than variation in propeller thrust in terms of lift generation. Also revealed was the ability to operate unstalled at very high angles of attack of $40^{\circ}-45^{\circ}$, or to achieve very high lift at much lower angle of attack to increase visibility and controllability. In order to provide greater flexibility in Super-STOL takeoffs and landings, the blown model also displayed the ability to interchange thrust and drag by varying blowing without any moving parts. A preliminary design study of this pneumatic vehicle based on the two technologies integrated into a simple Pneumatic Channel Wing configuration showed very strong Super-STOL potential. This paper presents these experimental results, discusses variations in the configuration geometry under development, and addresses additional considerations to extend this integrated technology to advanced design studies of PCW-type vehicles.
\end{abstract}

\section{Introduction / Background}

The ability to achieve Super-STOL or V/STOL capability with fixed-wing aircraft has been an attractive goal in the aerospace community for over 50 years. The impetus toward its achievement has historically been the numerous benefits associated with very-short to zerofield-length operations of non-rotary-wing aircraft. While such capability has direct application for military missions such as those of a tilt-rotor or tilt-wing aircraft, there also exists an additional need for simple/reliable/effective personal and business-sized SuperSTOL or VSTOL aircraft operating from remote or small sites as well as increasingly dense

\footnotetext{
* Principal Research Engineer; GTRI
}

** Principal Investigator; NASA LaRC 
urban environments. The development of simple, efficient aeropropulsive technology and corresponding low-speed control systems to make this possible is a goal which now seems practical due to technical breakthroughs in pneumatic and powered-lift aerodynamic technologies. This paper, presented at the NASA/ONR CC Workshop in March 2004, will discuss recent progress in the integration of high-lift, propulsive, and control systems, all employing common pneumatic techniques using Circulation Control blowing, into a promising Super-STOL configuration.

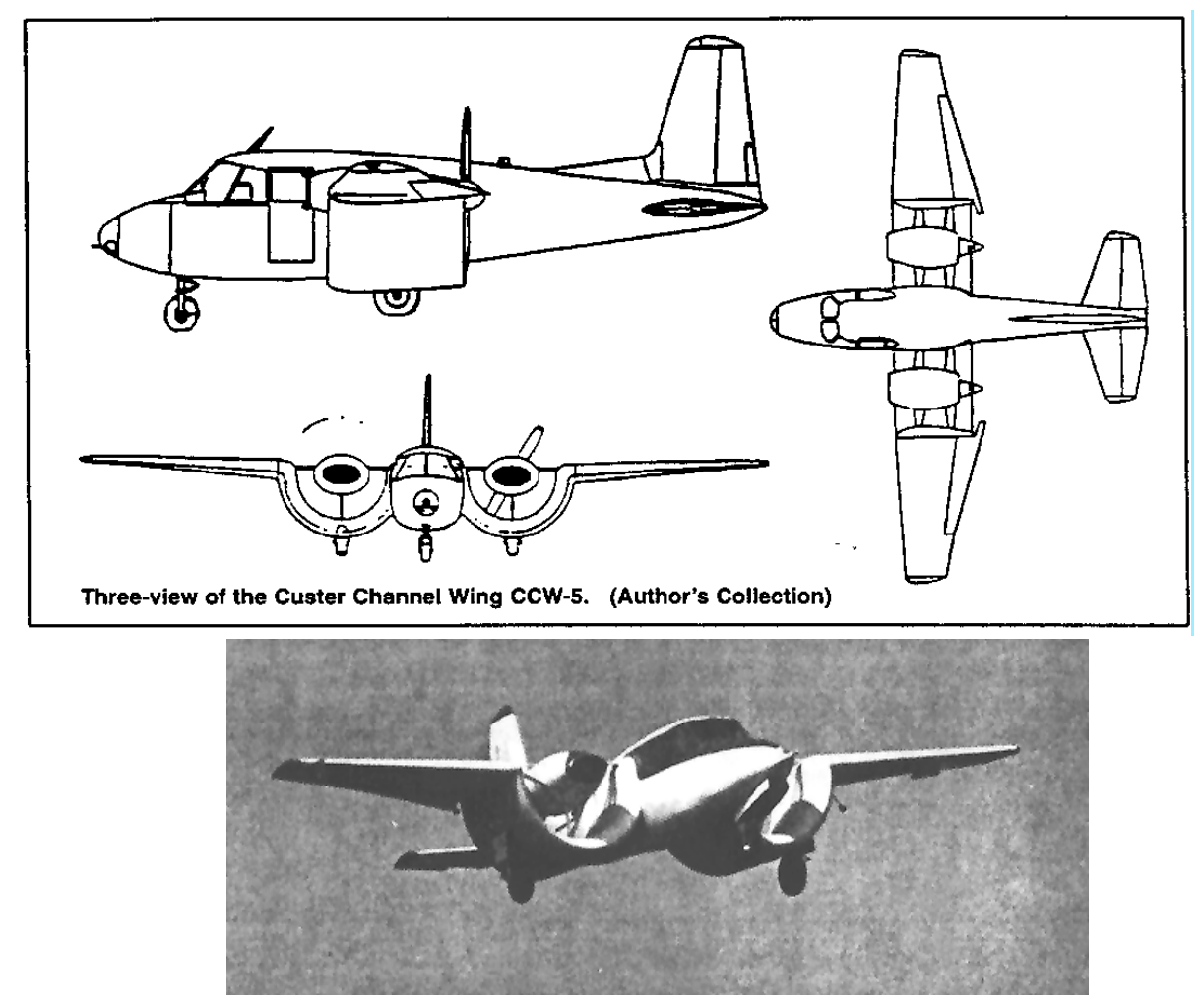

Figure 1- 3-View and in-flight photo of 1960s Custer Channel Wing Aircraft (Refs.1, 2 and 3)

Two promising technologies to evolve from earlier STOL/VSTOL research are the Custer Channel Wing powered-lift configuration and the Circulation Control Wing (CCW) pneumatic high-lift concept. Through innovative use of the propeller slipstream, the Channel Wing airplane developed by Willard Custer (Figure 1 and Refs. 1, 2, 3) was able to achieve significant lift coefficient and efficient downward thrust deflection without varying the high-lift configuration geometry. This powered-lift technology, tunnel-tested by NACA in 1953, (Ref. 1) and then flight-tested and further developed by Custer in the mid 1960's (Ref. 2), employed the Channel Wing concept shown in the sketch of Figure 2 (from Ref. 3). In essence, the propeller located at the very trailing edge of the $180^{\circ}$-arc circular channel in the wing further increased the velocity over the channel's upper surface and augmented the circulation and lift there in much the same manner as a deflected flap, but perhaps to a greater extent. Lift was also augmented by the deflected slipstream behind the channel such that

$$
\Delta \mathrm{C}_{\mathrm{L}}=\mathrm{C}_{\mathrm{T}} \sin \left(\alpha+\delta_{\text {slipstream }}\right)
$$




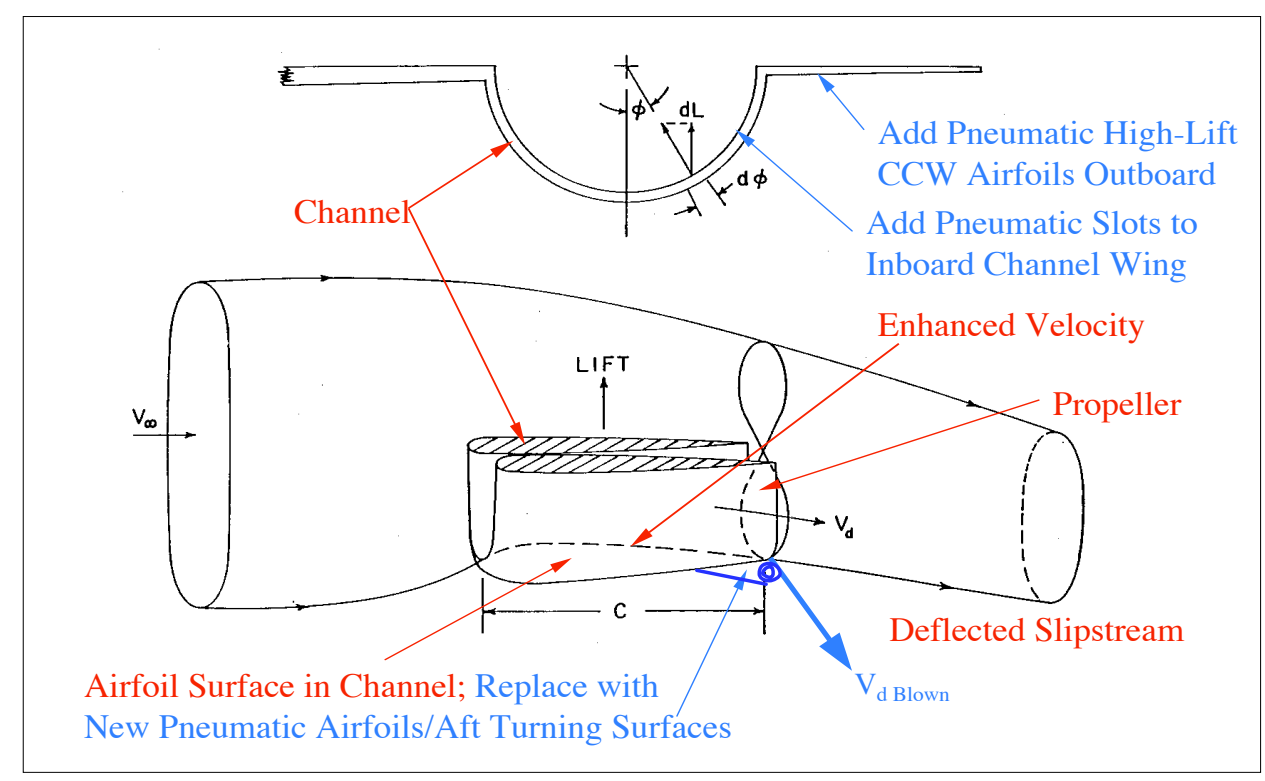

Figure 2- Basis of the Channel Wing Concept and Current Pneumatic Improvements (Blue)

However, while in-flight lift coefficients nearing 5 were generated by thrust coefficients also nearing 5 (Ref. 3), the flight-tested Custer Channel Wing aircraft demonstrated a number of drawbacks associated with low-speed handling, cruise drag, stability \& control, high-incidence operation, and one-engine-out scenarios, including:

- much of the high $C_{L}$ was from redirected thrust, less was from circulation lift augmentation

- high cruise drag could result from the channel's extra surface area

- asymmetric thrust yields asymmetric moments \& instability

- channel leading-edge and trailing-edge separation could occur at high angle of attack, $\alpha$

- poor low-speed control from conventional aerodynamic surfaces at low speeds

- nose-down pitch from aft propeller loading on the wing

- non-uniform flow around the prop at high $\alpha$

- poor lift/drag ratio

- high-angle-of-attack operation could cause poor visibility and control

- one-engine-out control problems

To alleviate these shortcomings, preliminary research has been accomplished under a NASA-Langley-sponsored program at Georgia Tech Research Institute (GTRI) which has investigated adapting Circulation Control pneumatic technology (Figure 3 and Refs. 4 and 5, for example) to dramatically improve the Channel Wing configuration. As Figure 2 shows, the new pneumatic configuration (in blue) thus developed combines blowing on curved surfaces at the channel trailing edge to greatly augment the lift and thrust deflection without using high angle of attack. It also employs blown Circulation Control Wing technology on the 


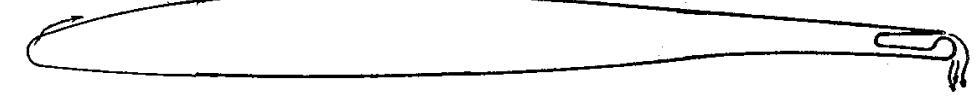

TANGENTIAL BLOWING OVER ROUNDED TRAILING EDGE SURFACE
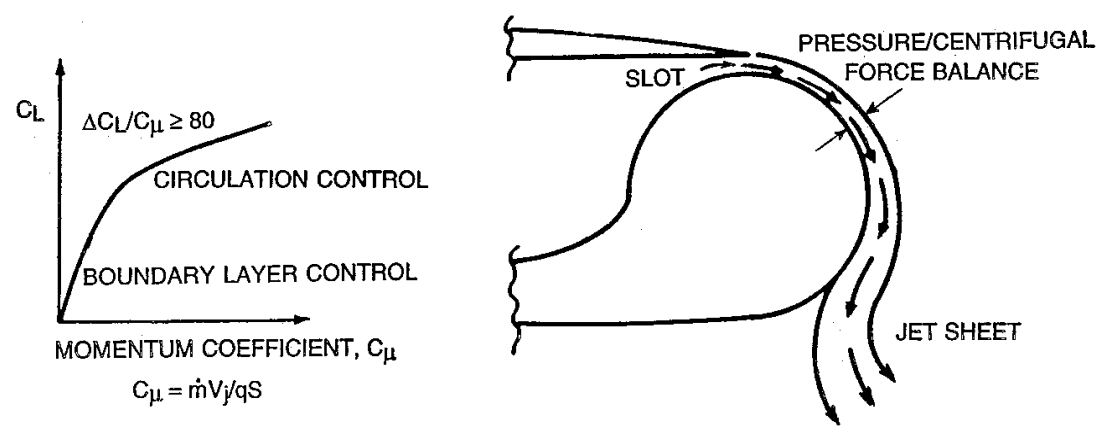

Figure 3-Basics of Circulation Control Pneumatic Technology
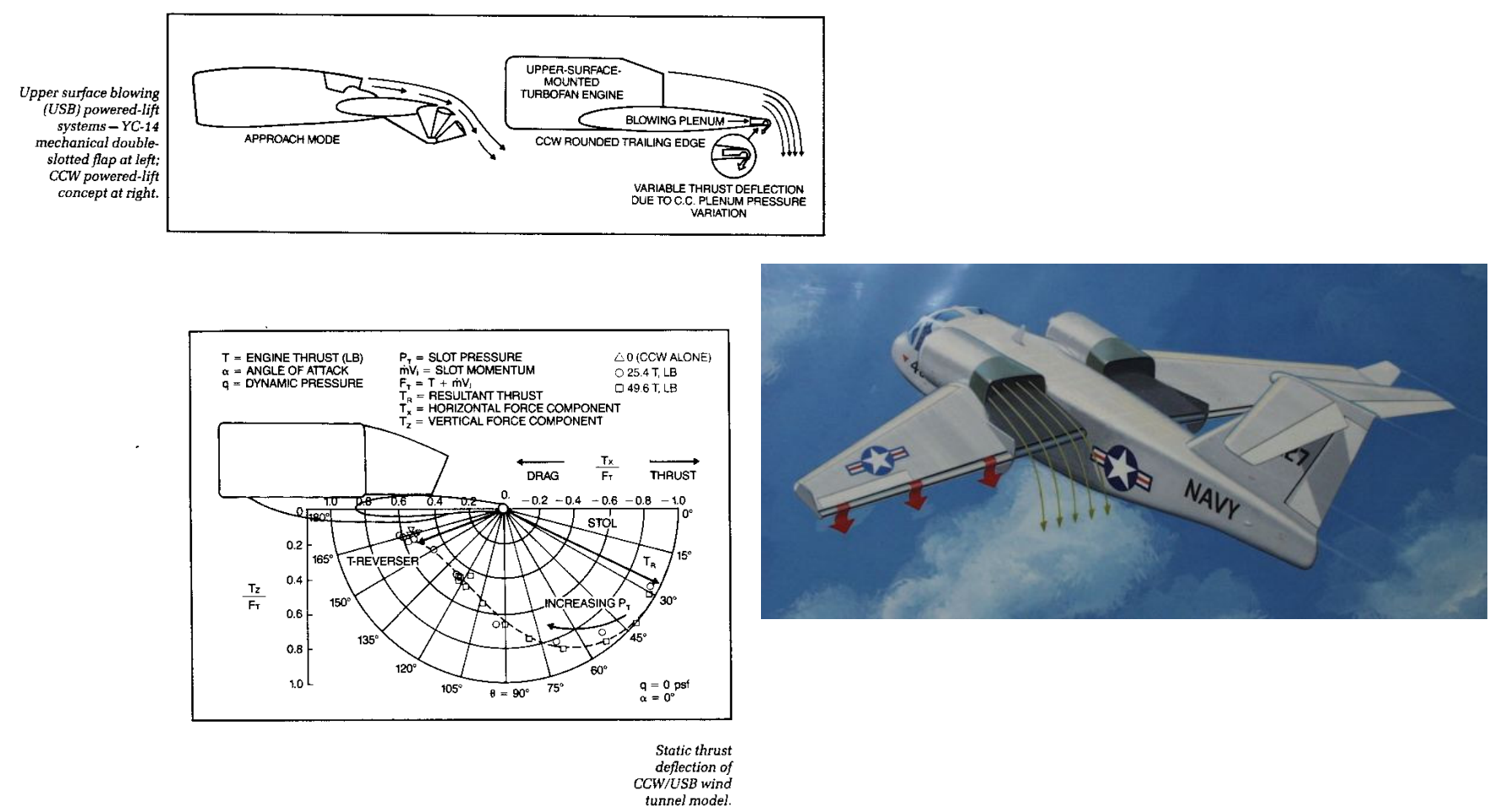

Fig. 4 - Previously Developed Circulation Control Wing/ Upper Surface Blowing

Powered-Lift Concept (Ref. 6)

outboard wing panels to further augment lift and low-speed controllability while providing additional drag when needed for slow-speed approaches down steep glide slopes for Super-STOL.

This channel thrust turning and lift augmentation are based on the CCW/Upper Surface Blowing (USB) concept of Figure 4, where tangential blowing on a highly curved trailing edge behind a jet engine augments flow field entrainment, increases circulation and 
deflects thrust to add more incremental lift. Thrust deflection angles of $165^{\circ}$ produced by blowing were measured experimentally on wind-tunnel models (Refs. 5 and 6). This concept provides pneumatic STOL, VSTOL and thrust-reversing capabilities without any moving parts. CCW alone (Figure 3 ) employs a similar tangential-blowing configuration but without the pneumatic thrust deflection. CCW airfoils have generated measured 2-D lift augmentations of 80 times the input blowing momentum (Refs. 4 and 5). When flight-tested on an A-6 flight demonstrator, CCW showed a 140\% increase in useable high-lift, employing only half of the bleed air available from the aircraft's standard turbojet engines (Ref. 8). Figure 2 shows how these blown flow-entrainment devices would be arranged to enhance the effectiveness of the Pneumatic Channel Wing (PCW) configuration. In addition, the CCW lift capability can be applied differentially outboard to generate very large rolling and yawing moments, which are essential for controlled flight at the very low speeds of Super-STOL.

Based on earlier CCW/USB wind-tunnel and full-scale data (Figure 4 and Refs. 6 and 7) and CCW flight test data from the A-6 STOL-demonstrator program (Ref. 8), the predicted lift and drag capabilities for the Pneumatic Channel Wing configuration were expected to offer great Super-STOL promise. Reference 9 details these early predictions before the current wind-tunnel test data were available; these implied $C_{L}$ values approaching 9-10 for a Pneumatic Channel Wing aircraft with blowing on outboard CCW wing panels at relatively low aircraft angle of attack. Higher $C_{L}$ values were possible at higher thrust coefficients if higher $\alpha$ values were used due to the additional vectored thrust component. Again, for comparison, the Custer Channel Wing aircraft generated in-flight $C_{L}$ of 4.9; a conventional slotted flap on this wing geometry would generate $C_{L}$ from 2 to 3 . Initial takeoff predictions (Ref. 9) showed that these PCW capabilities could produce very-short hot-day takeoff ground rolls for typical mission weights, and even zero ground roll under certain conditions.

As part of an ongoing program for NASA Langley Research Center to develop this Pneumatic Channel Wing concept, GTRI and NASA have teamed in an experimental development program being conducted at GTRI, which has provided aerodynamic and propulsive data input for design studies being conducted at both NASA and GTRI. This current paper will summarize these experimental results and discuss effects deriving from variations in PCW geometry, propeller thrust and channel blowing.

\section{Experimental Apparatus and Test Techniques}

A wind-tunnel development/evaluation program was conducted at GTRI on a generic twin-engine Super-STOL-type transport configuration, Figure 5, using the 0.075-scale semispan model shown in Figure 6 . Here, a variable-speed electric motor was installed in the nacelle, which could be located at various positions in the channel, and which drove interchangeable 2-bladed, 3-bladed or 4-bladed propellers of various diameters and pitch. Also variable was the height of the blowing slot located at $95 \%$ of the channel chord length, as well as the blowing momentum coefficient and portions of the slot arc length which were blown. Behind the slot, the rounded trailing edge curved only $90^{\circ}$ (rather than the more conventional $180^{\circ}$ of typical CCW configurations) for an anticipated maximum thrust deflection of around $\left(90^{\circ}+\alpha\right)$. It was already known (Fig. 4) that thrust deflections up to $165^{\circ}$ yielded by blowing were a possibility. Here, the momentum coefficient is defined as 


$$
\begin{gathered}
\mathrm{C}_{\mu}=\left(\text { mass flow rate }{ }^{*} \text { jet velocity }\right) /(\text { dynamic pressure * wing planform area }) \\
=\mathrm{m} \mathrm{Vj} /(\mathrm{qS}) .
\end{gathered}
$$

This semi-span model configuration (Fig. 6) was mounted on an under-floor balance with air supplies and automated pitch table in the GTRI Model Test Facility 30" x 43" x 90" test section. Tunnel wall boundary layer near the test section floor was eliminated by use of tangential floor blowing. In a follow-on version of this configuration, both the leading edge and the trailing edge of the outboard $\mathrm{CCW}$ wing section were also blown for separation control. The emphasis in the following data is on the performance of the inboard blown Pneumatic Channel Wing configuration, but performance of the outboard CCW sections to further augment lift is also shown.

\section{Wind-Tunnel Evaluations and Results}

Test techniques employed in the subsonic tunnel evaluation of this pneumatic poweredlift model are similar to those employed and described in Refs. 10 and 11 for blown airfoil and semi-span models, except that special additional techniques were employed to account for the installation of the active propeller in the channel (see below). Some 980 wind-tunnel runs (including propeller calibrations) have now been conducted during three test programs at GTRI to develop these blown-configuration geometries and to evaluate their aeropropulsive, flight-trim and control characteristics. A typical run consisted of a sweep (incremental variation) of prop thrust or blowing pressure at constant angle of attack and wind speed. Also, angle of attack sweeps or dynamic pressure (velocity) sweeps were run at constant thrust and blowing coefficients, $\mathrm{C}_{\top}$ and $\mathrm{C}_{\mu}$. Numerous runs were made with varying tail configurations to evaluate pitch trim and control. Typical test results are presented in the following sections to demonstrate how these various parameters affected overall performance.
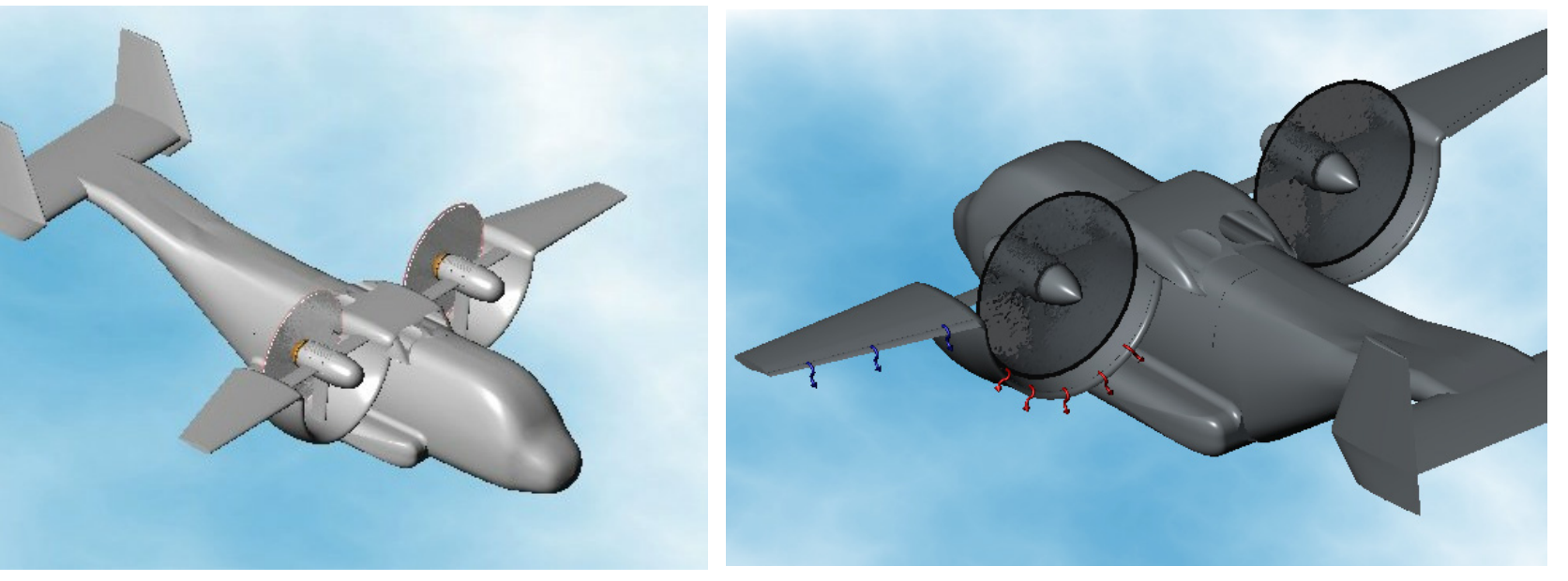

Fig. 5 - Conceptual Pneumatic Channel Wing Super-STOL Transport Configuration 

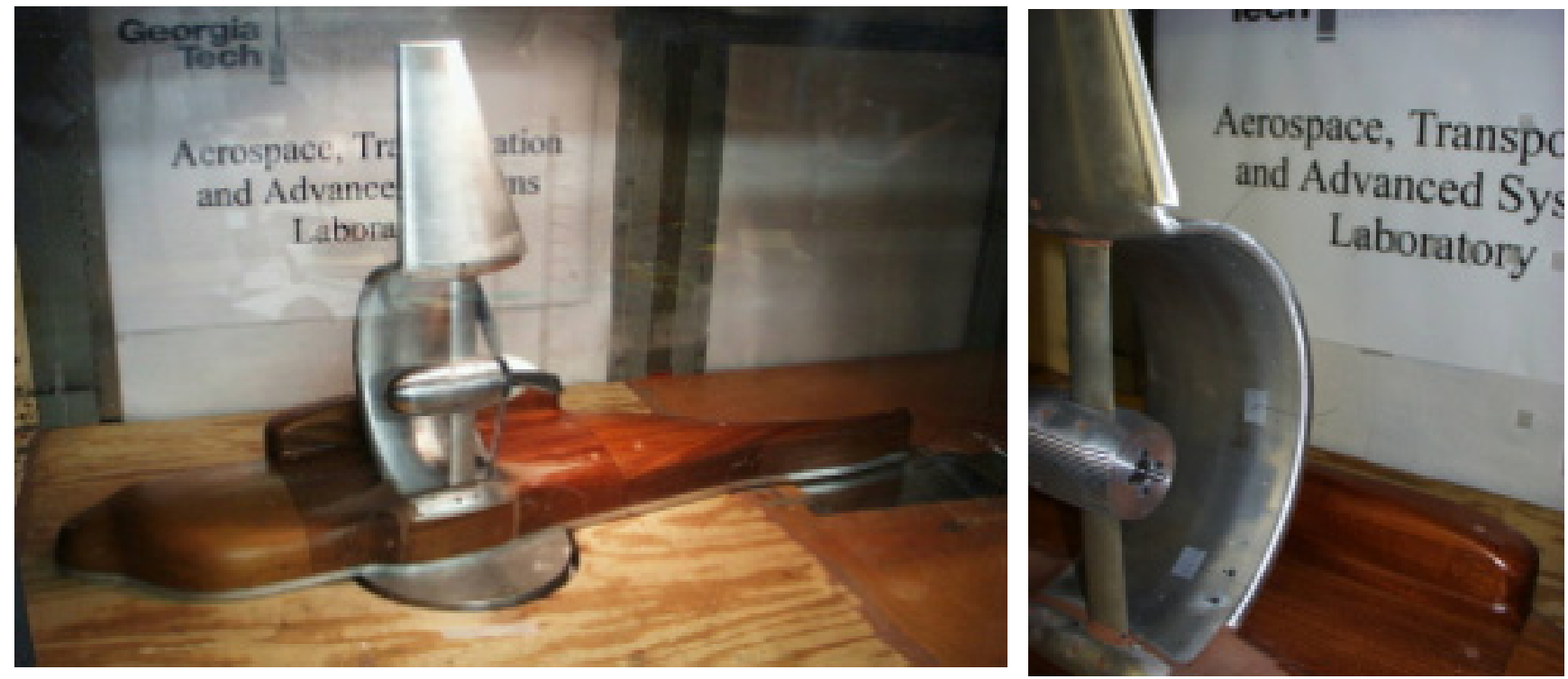

Fig. 6 - Pneumatic Channel Wing/CCW Semi-span Model Installation in GTRI Model Test Facility Research Tunnel (3-bladed prop with Unblown Outboard CCW ), plus Jet Flow Turning in Channel (black tufts)

\section{Tunnel Test Results, Outboard Wing ON}

In Figures $7 \mathrm{a}$ and $7 \mathrm{~b}$ are shown the effects on lift and drag coefficients of blowing the channel trailing edge without the prop installed (i.e., $\mathrm{C}_{\top}=0$ ), but with the engine nacelle in place, Fig. 6. Notice the ability of the blowing to more than double the $C_{L \max }$ of the unblown configuration with virtually no reduction in the stall angle, $a_{\text {stall }}$. The $C_{L}$ values shown are comparable to or greater than those which would normally be generated by more-complex moving mechanical flaps. Notice also the ability of the blowing at $\alpha=0^{\circ}$ to increase $C_{L}$ by a factor of nearly 10 over the unblown value. At $\alpha=0^{\circ}$, blowing at $C_{\mu}=0.30$ yields $50 \%$ more $C_{L}$ than the $\mathrm{C}_{\mathrm{Lmax}}$ of the unblown configuration. In Figure $7 \mathrm{~b}$, the drag polars at constant $\mathrm{C}_{\mu}$ are typically quadratic in $\mathrm{C}_{\mathrm{L}}$. Earlier in $\alpha$ than where the stall begins, they follow essentially the same single curve, using blowing to progress to each successive higher $C_{L}$ region.

Addition of the propeller to the channel brings into play the powered-lift characteristics of the Pneumatic Channel Wing configuration. Figure 8, for $\alpha=0^{\circ}$, shows the variations in $C_{L}$ and $C_{D}$ with thrust coefficient $C_{T}$ for fixed values of blowing coefficient. Here, in order to recognize the direct thrust component to lift and drag, thrust coefficient is defined as $\mathrm{C}_{\mathrm{T}}=$ $\mathrm{T} /(\mathrm{qS})$, where $\mathrm{T}$ is the calibrated uninstalled wind-on prop-alone (not-in-the-channel) thrust at the proper advance ratio, i. e., representative test dynamic pressure, q. The reference area $S$ is the wing semi-planform area. These thrust values were determined prior to installation in the channel by testing the prop alone in the tunnel at various RPMs and tunnel speeds. 


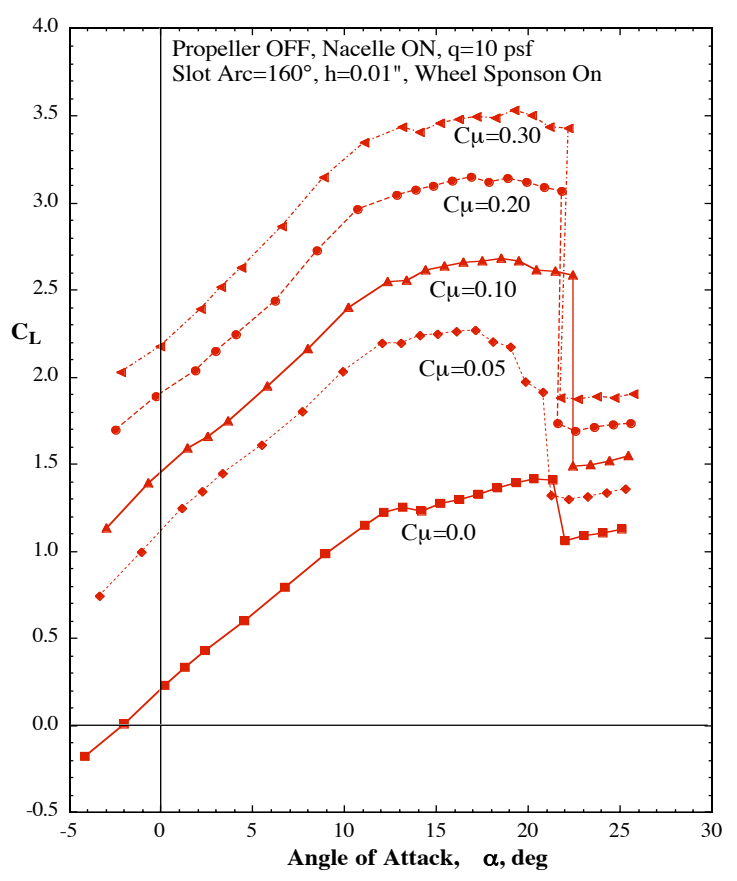

(a) Lift vs $\alpha$

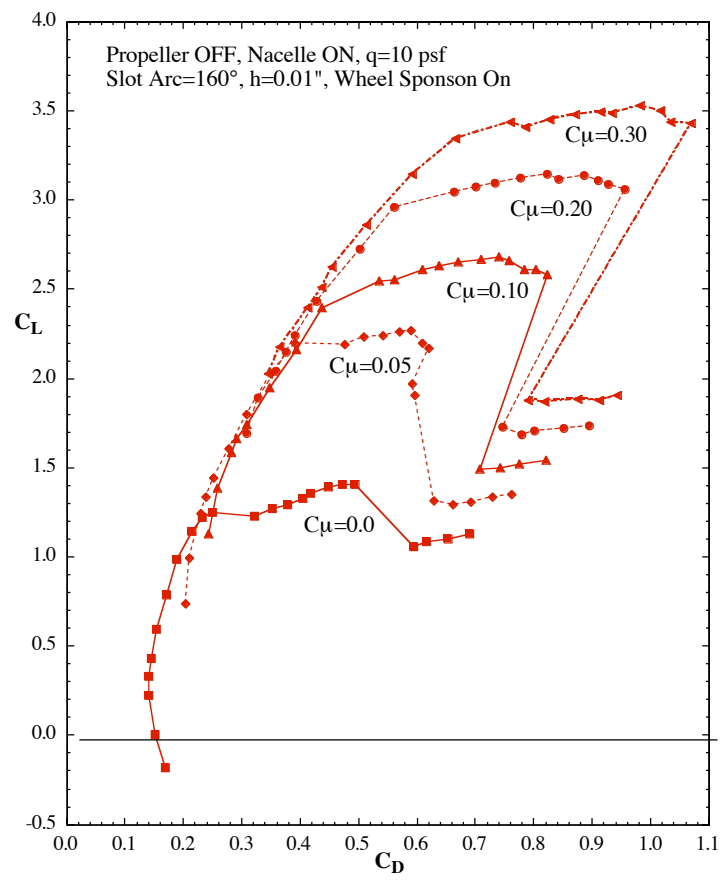

( b)Lift-Drag Polars

Fig. 7- Measured Blown Lift and Drag Capabilities of the Pneumatic Channel Wing Model Without the Propeller Installed

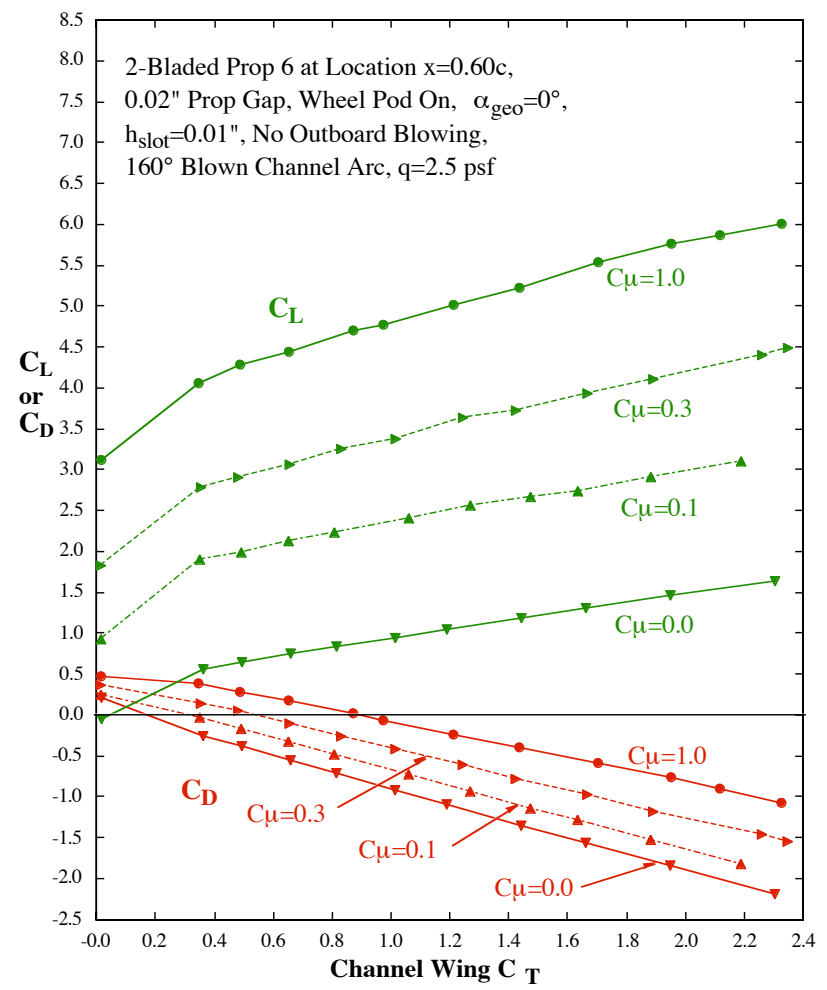

Fig. 8- Effects of Prop Thrust Variation on Lift and Drag at Constant Blowing $(\mathrm{C} \mu)$ and $\alpha=0^{\circ}$ 


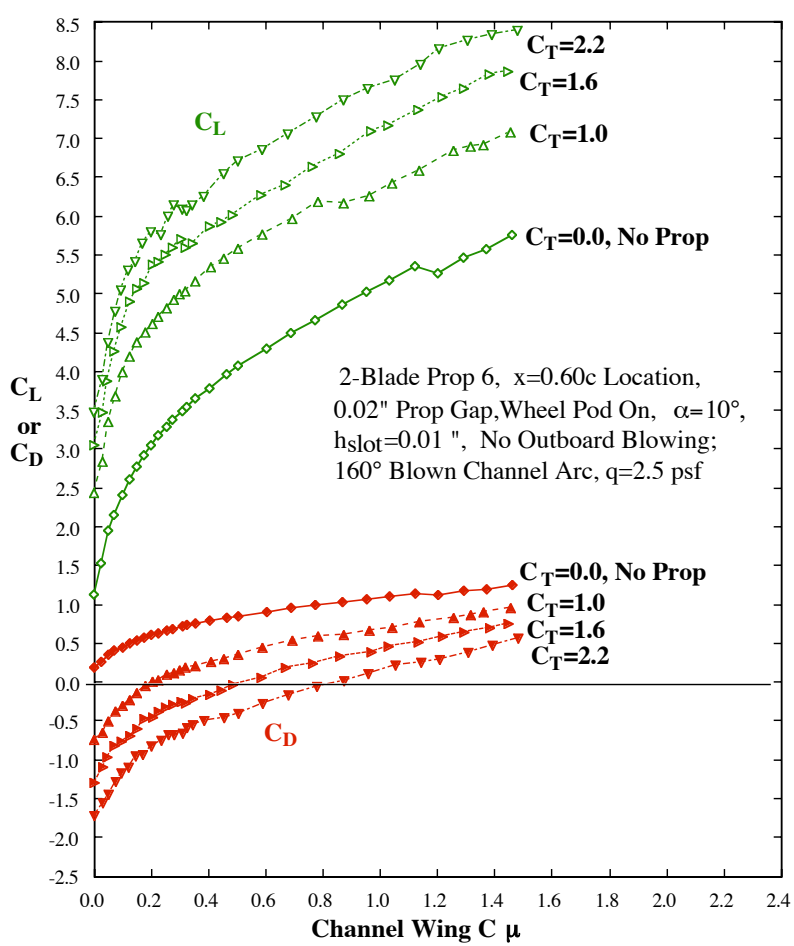

Fig. 9 - Effects of Blowing Variation on Lift and Drag at Constant $\mathrm{C}_{\mathrm{T}}$ and $\alpha=10^{\circ}$

Then, calibration curves of T vs RPM were input to the data reduction program at given test wind speeds. Thus $\mathrm{C}_{T}, \mathrm{C}_{\mathrm{L}}$ and $\mathrm{C}_{\mathrm{D}}$ are directly comparable on a common reference basis to determine force contributions from installed thrust. This avoids the difficulty which would be caused by using the standard helicopter thrust coefficient, based on rotor (or prop) geometry rather than wing area. Also, note that measured $C_{D}$ thus obviously includes the input thrust, which cannot reasonably be separated from the aerodynamic drag alone once the prop is in the channel. Measured $C_{D}$ can thus be (and sometimes is) negative. After the initial low values of $\mathrm{C}_{T}$ are exceeded, $\mathrm{C}_{\mathrm{L}}$ increases nearly linear with $\mathrm{C}_{T}$, and $\mathrm{C}_{D}$ reduces nearly linearly. (This implies that at a constant $\mathrm{C} \mu$, the thrust deflection angle is nearly constant.)

Figure 9 shows that incremental lift augmentation due to blowing $\left(\mathrm{C}_{\mu}\right)$ is much greater than due to $\mathrm{C}_{T}$ (Figure 8). Here at $\mathrm{C}_{T}=2.2$, the blown configuration generates $\mathrm{C}_{\mathrm{L}}$ around 8.5 at $\alpha=10^{\circ}$. The flight-tested Custer Channel Wing (Ref. 3) generated roughly 1/3 this $C_{L}$ at this $C_{T}$, but also required $\alpha=24^{\circ}-25^{\circ}$. Note also that increased blowing at a constant $\mathrm{C}_{\mathrm{T}}$ yields increased drag (rather than thrust recovery), which can be quite essential for Super-STOL approaches and short landings. These lift comparisons in Figures 8 and 9 show that lift increases more efficiently by increasing blowing than by increasing thrust. In the Figure 10 plot is shown the variation in lift and drag with angle of attack for the blown powered-lift configuration in comparison to the unblown baseline configuration without the prop. Here, flow visualization showed that the initial stall $\left(\alpha=15^{\circ}-17^{\circ}\right)$ seen for most of the lift 

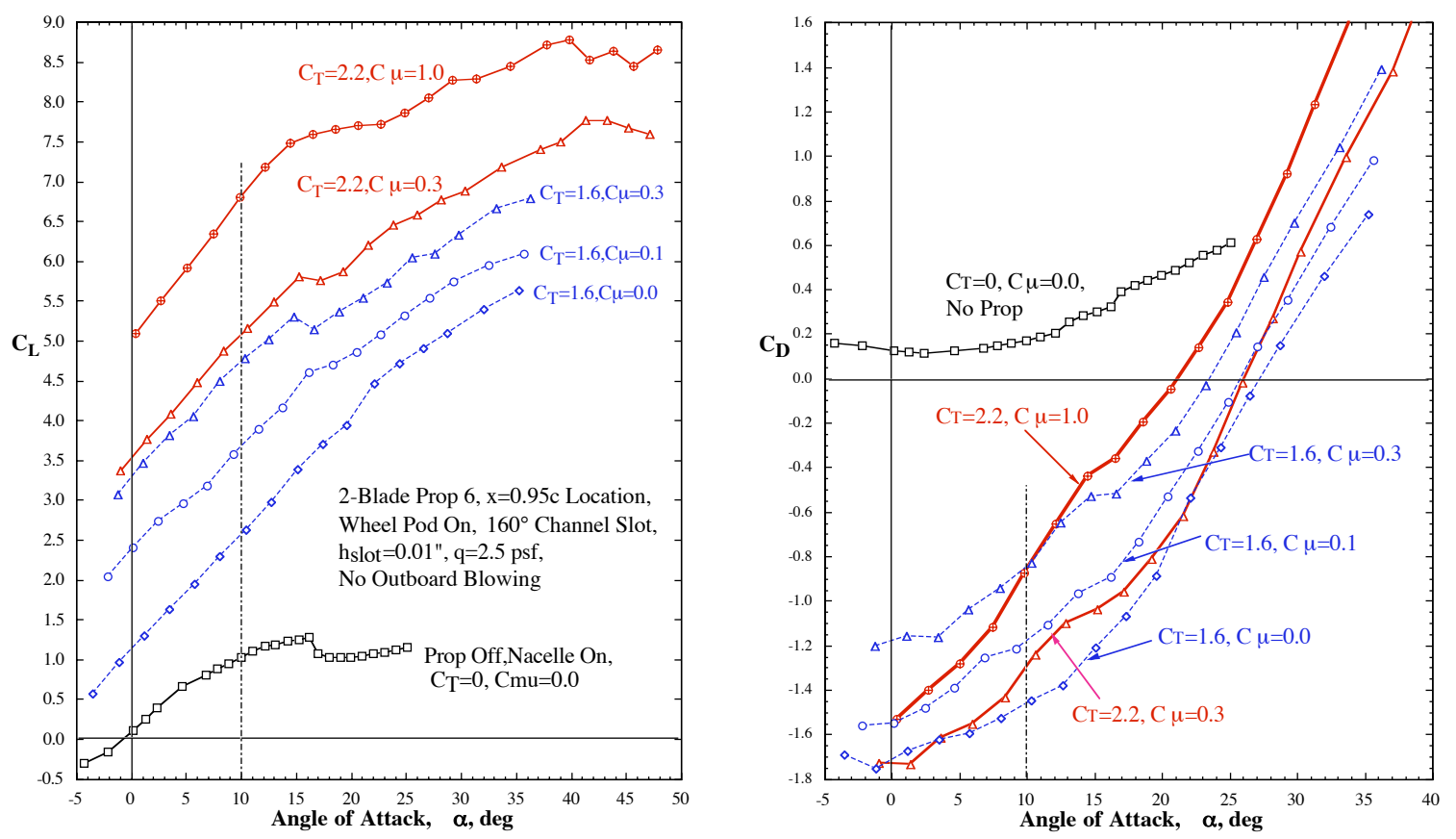

Fig. 10 - Effects of Blowing, $\mathrm{C}_{\mathrm{T}}$, and $\alpha$ on Lift Coefficient, Stall Angle and Drag Coefficient for Pneumatic Channel Wing Model with Unblown Outboard Wing

curves corresponded to stall of the outboard unblown wing section, while the blown channel wing section then continued on to stall angles of $40^{\circ}-45^{\circ}$ and $C_{L}$ values of 8.5 to 9 . Notice that $C_{D}$ (including thrust) increases from negative to positive values as incidence increases.

Figure 11 shows the effect on lift and drag of increasing the circular arc length of the blown slot around the channel at a given prop longitudinal location $(x / c=0.95)$, where the maximum slot arc of $160^{\circ}$ was most effective. Blowing of more than $160^{\circ}$ of channel arc was not appropriate on this model because the last $20^{\circ}$ of inboard arc was along the channel right next to the fuselage, and blowing there would do little more than bounce off the fuselage.

The effect on increased tail-off pitching moment caused by suction loading on the aft of the channel (either by blowing, prop slipstream, or both) is shown in Figure 12 as a function of $\mathrm{C}_{T}$ and $\mathrm{C}_{\mu}$, all at $\alpha=0^{\circ}$. These moments are referred to the channel's quarterchord location (c/4), and confirm the typical trend of this type of blown configuration: large nose-down $\mathrm{CM}_{\mathrm{M}}$ which, while it does make the aircraft much more stable longitudinally, causes concern with pitch trim. It is for this reason that additional experimental evaluations were conducted tail-on to investigate increased longitudinal trim capabilities. All data presented so far have been tail-off. Also a second investigation was conducted with leadingedge blowing installed on the outboard wing CCW portion to provide counteracting nose-up pitch for trim, as well as for leading-edge separation prevention. 


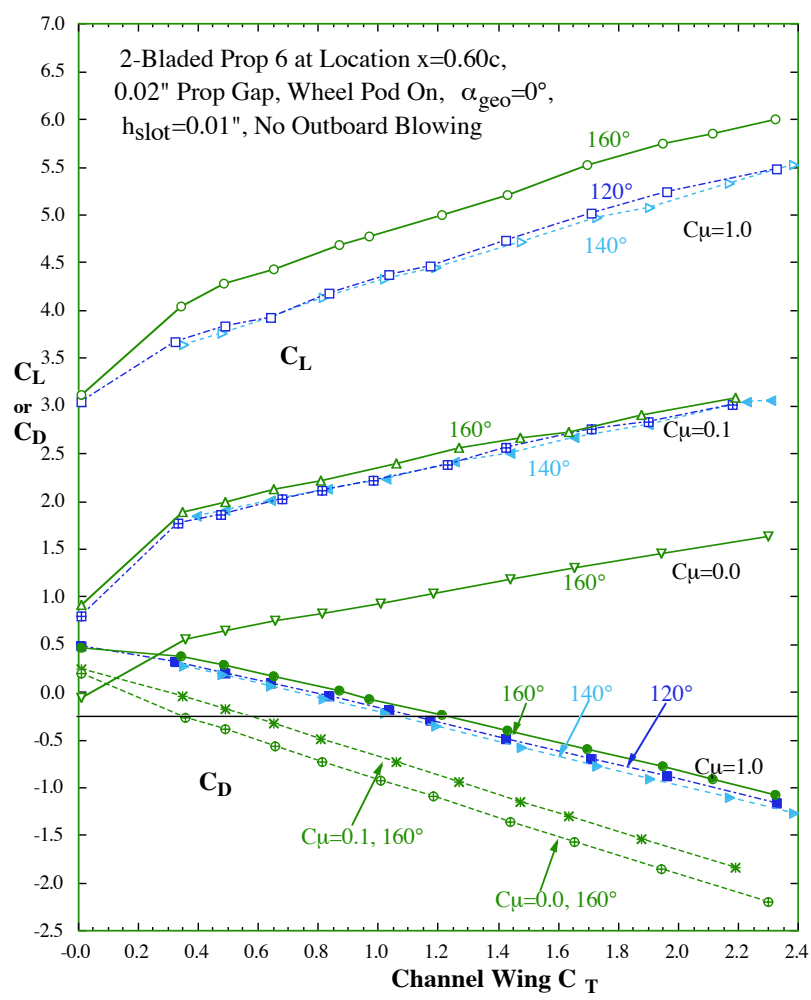

(a) Prop \& Nacelle Installed

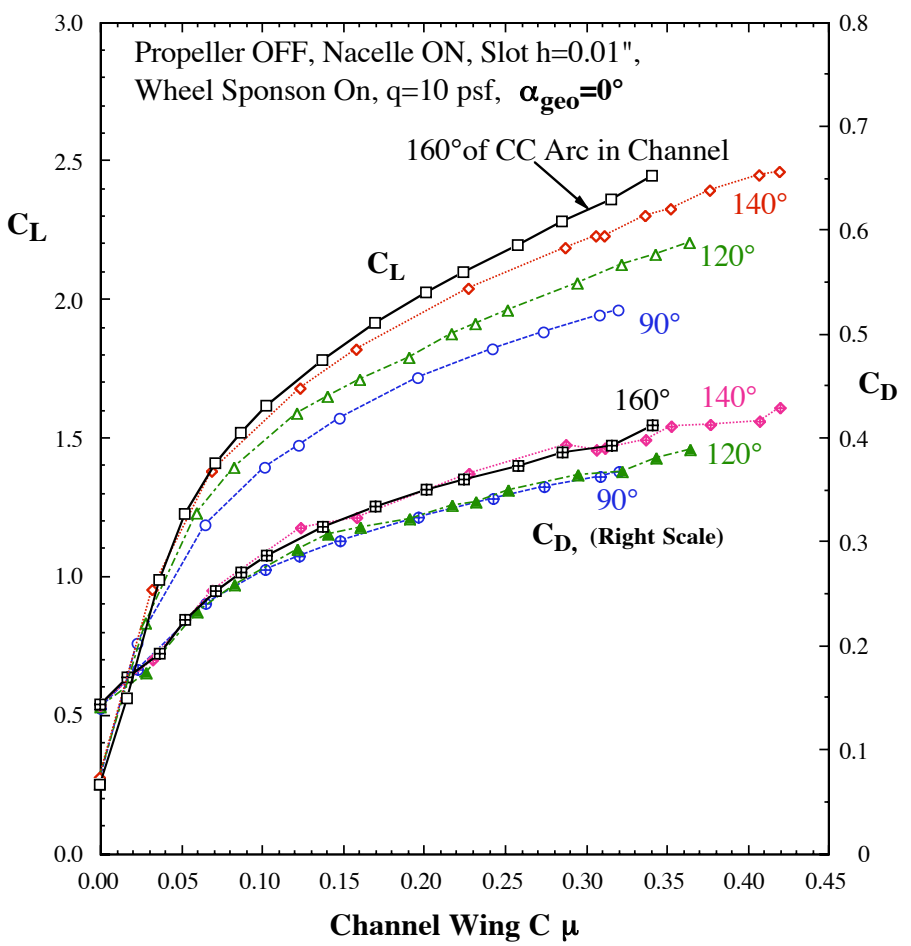

(b) Prop OFF but nacelle installed

Fig. 11 - Effects on Lift and Drag of Varying Blown Channel Slot Arc Length at Constant $\mathrm{C} \mu$ and at $\alpha=0^{\circ}$

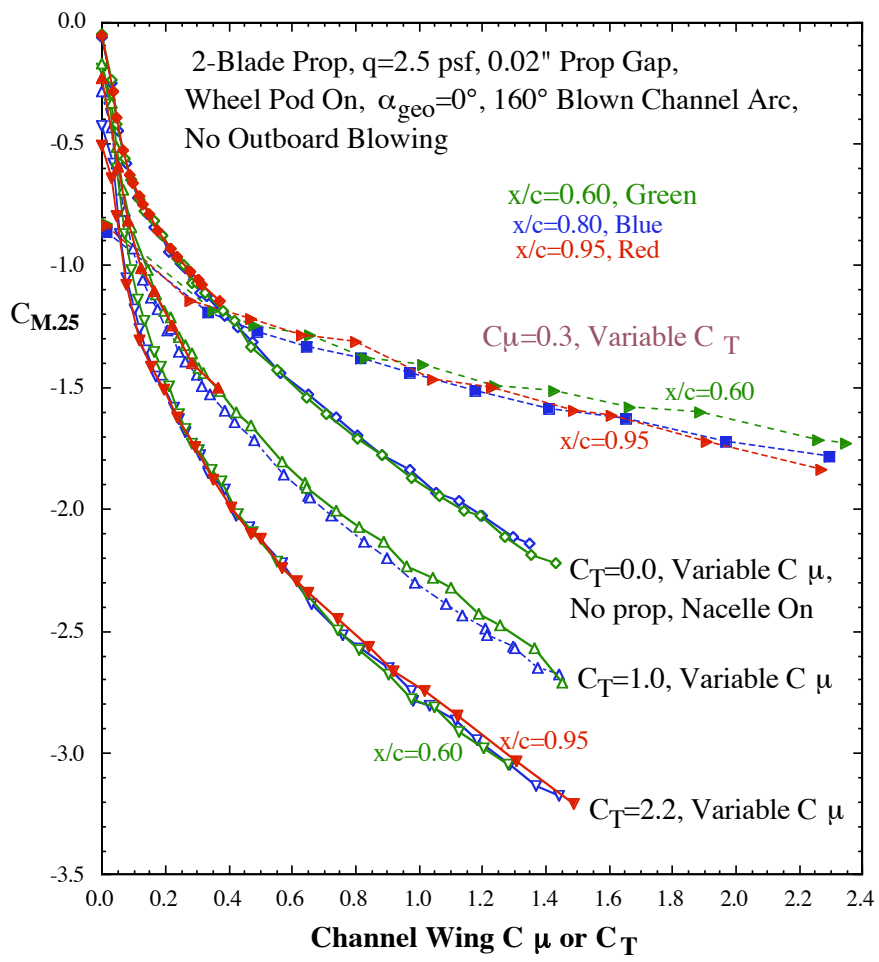

Fig. 12 - Effects of Prop/Nacelle Location, Blowing and Thrust on Quarter-Chord Pitching Moment, $\alpha=0^{\circ}$ 


\section{Tunnel Test Results, Channel Wing Only}

Higher non-dimensional thrust coefficient values were available when the channel-only configuration was tested (fuselage, blown channel and prop, but with no outboard CCW panels) since the reference planform area of the wing was also reduced. This allowed $C_{T}$ of $\sim 3$ for the channel-only vehicle, and as Figure 13 shows, lift coefficients nearing 11 were measured with a conventional horizontal tail installed at the mid-vertical location on the aft fuselage. Needless to say, not all of the lift values shown in Figure 13 (right plot) are trimmed longitudinally. Furthermore, for the $\mathrm{C}_{\mathrm{T}}=3$ case with blowing on, the conventional tail of the aircraft stalled experimentally over much of the lower $\alpha$ range (more on this below).

The possible inability to longitudinally trim these Super STOL aircraft was pointed out as a problem of blown systems in Refs. 7 and 8 . It is further emphasized in Figure 13,
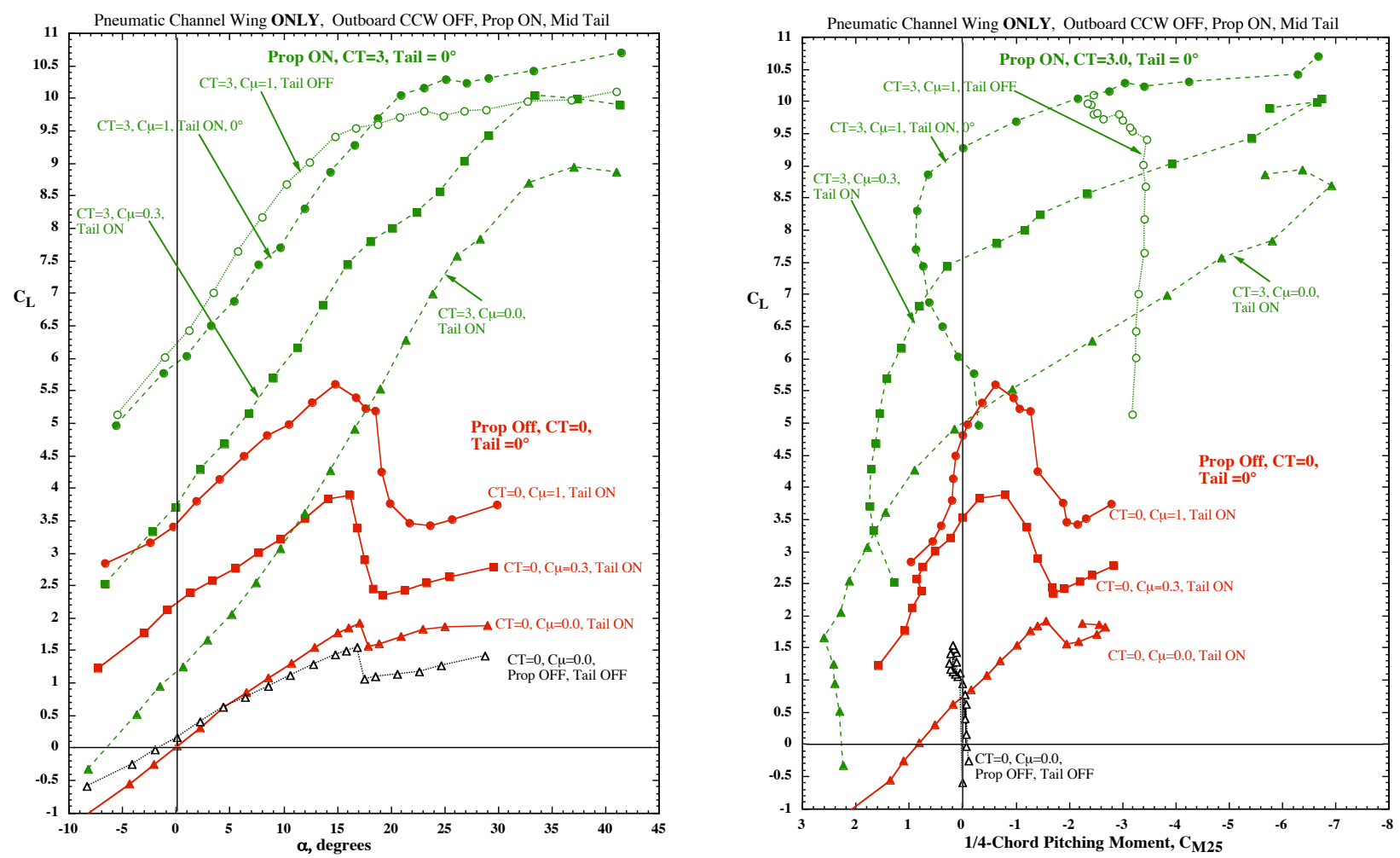

Figure 13 -Effect of Thrust and/or Blowing Increase on Lift \& Pitching Moment Variation with $\alpha$ for Channel-Wing-Only Configuration (No Outboard Wing Panels) with Tail at Mid-location, $\mathrm{i}_{\mathrm{T}}=0^{\circ}$

where the large suction on the aft-loaded blown channel (and blown wing, if present) produces very large nose-down pitching moments (see the tail-off curve). Even though this can produce improved longitudinal stability, these moments must also be trimmed. Horizontal tail investigations were conducted as part of this 3-D model development plan in hopes of determining tail location and configuration to provide enough nose-up pitch to trim the vehicle. Several horizontal tail configurations (one without an elevator, a second with a $20^{\circ}$-up elevator $\left[\delta_{\text {elev }}=+20^{\circ}\right]$, and a third with an inverted leading edge droop) were designed and fabricated.. As Figure 14 shows, these could be mounted on a vertical center plate yielding variation in both tail incidence $\left(\mathrm{i}_{\mathrm{T}}\right)$ and vertical position in the propeller slipstream. High, mid-fuselage, and low-tail positions were tested. Testing of these tail-on configurations over a range of tail parameters revealed that a low-tail position immersed in 
the prop slipstream and dynamic pressure was more effective than the higher tail (Figure 15), but the lower tail also experienced more leading-edge stall for the same reason. This tail stall prevents the vehicle from being trimmed at this higher blowing condition (here with the outboard CCW wing on again). Considerable videotaping of flow visualization tufts on the tail revealed these problem areas and led to the development of the inverted-droop (drooped upward) leading-edge modification for the tail. Keeping the tail LE attached allows positive nose-up pitch and thus trim to be generated for the vehicle over a much wider range of lower $\alpha$ values. For the Channel-Wing-Only model with the modified tail, trimmed $C_{L}$ values greater than 9 are thus seen (Figure 16), but much of this data is still untrimmed, and again the low tail with no LE mods is fully stalled. Thus, this data implies that further tail development (perhaps including LE blowing to prevent the tail stall without mechanical LE fixes) is needed to trim in this high $C_{L}$ range at all vehicle angles of attack.
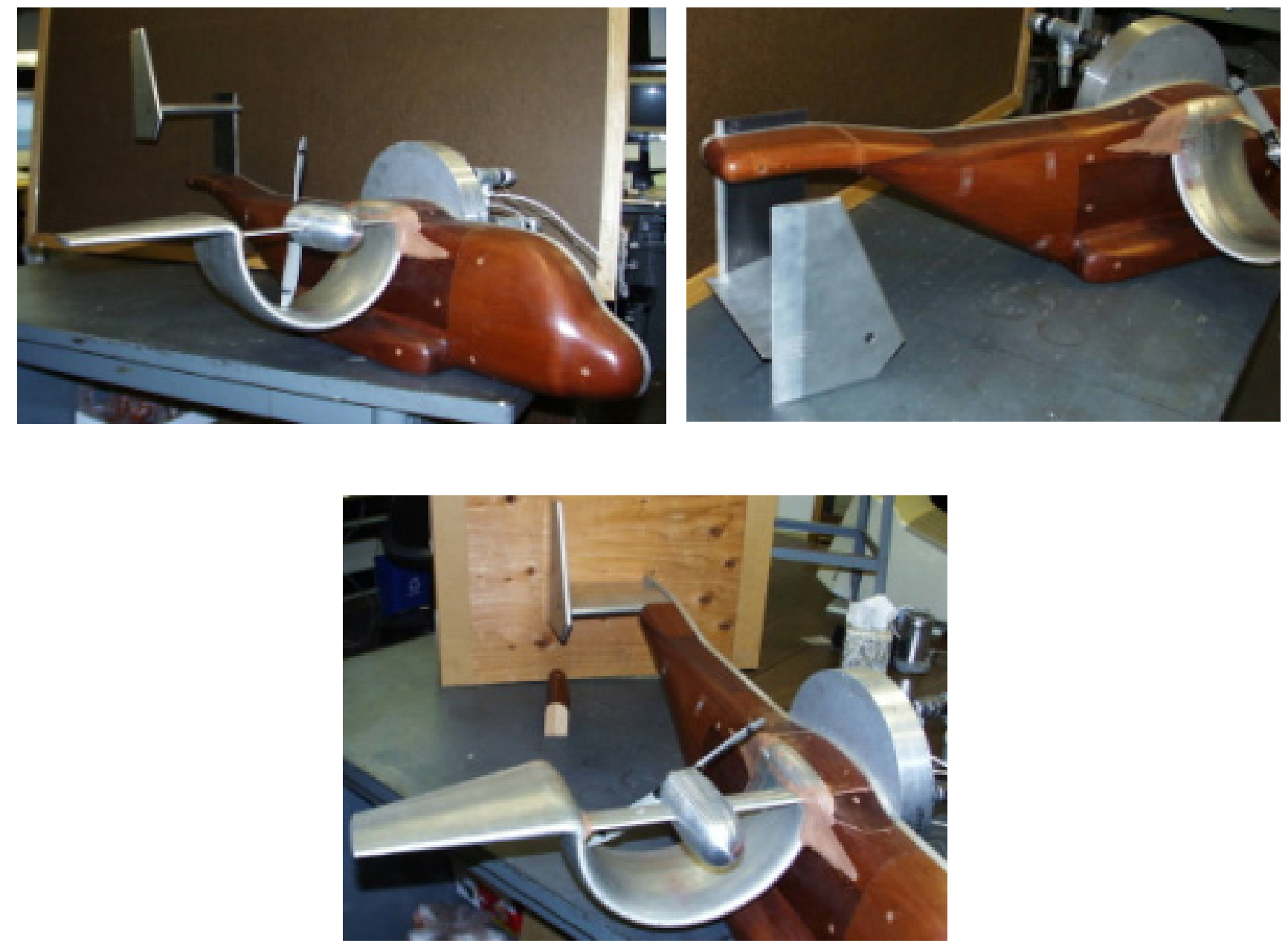

Figure 14 - Horizontal Tail Configurations Evaluated: High Tail; Low Tail; Mid-fuselage Tail, Outboard CCW ON 


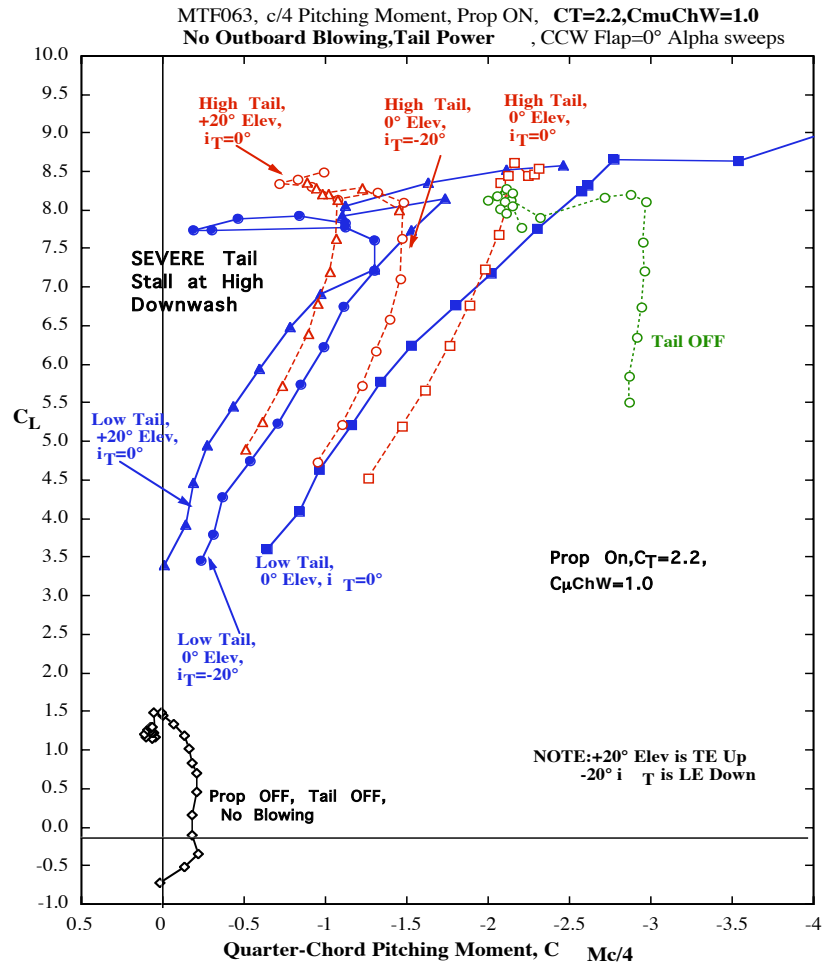

Figure 15 - Comparison of High and Low Tail Position on Pneumatic Channel Wing Configuration with Unblown Outboard Wing and Horizontal Tail
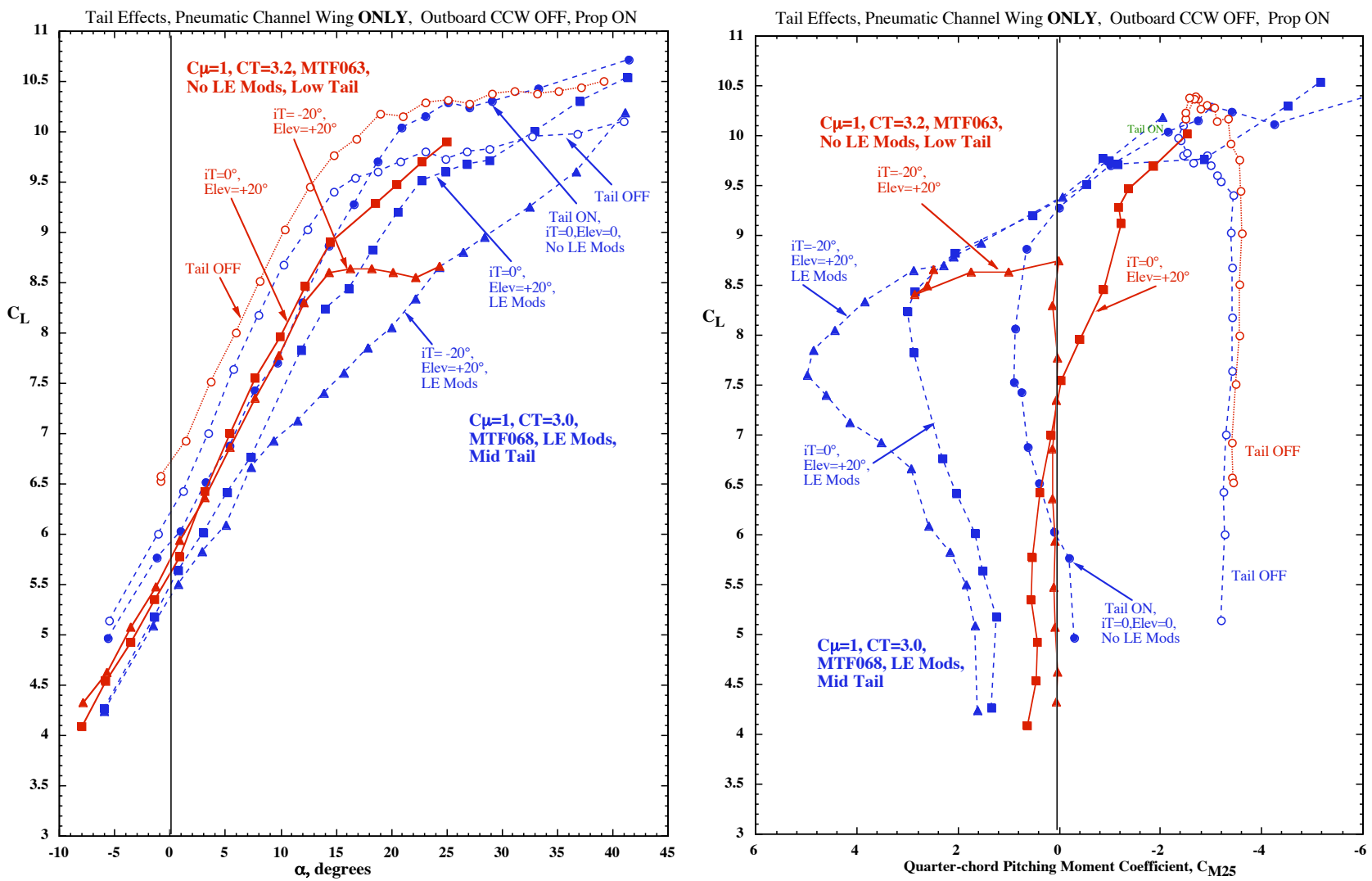

Figure 16 - Comparative Lift and 1/4-Chord Pitching Moment Coefficients of Pneumatic Channel Wing; No Outboard CCW, with and without Tail LE Modifications 


\section{Tunnel Test Results: Flow Attachment}

An additional series of flow visualizations was conducted to further identify means to prevent separated flow fields on the wing during high-lift generation. Figure 17 data show that the flow at the channel leading edge is entrained to the point where LE separation is prevented up until $\alpha=35-40^{\circ}$ or more, but that the outboard CCW is prone to stall there. Leading-edge blowing on this outboard $\mathrm{CCW}$ wing panel greatly entrained this flowfield as well. Figure 18 flow visualization shows this severe separation at $\alpha=20^{\circ}$ for the unblown case (left photo), while blowing the leading edge completely re-attached the flowfield there.

An additional means of trim and control was investigated for the Pneumatic Channel Wing. This means merely offsets these large nose-down pitching moments (seen in Figures 13,15 , and 16) by moving the aircraft center of gravity aft to trim, with no tail installed. Aft cg movement was previously performed for flight tests of the A-6/CC Wing aircraft, but with the tail on, Ref. 8. Figure 19 shows data for the $\mathrm{C}_{T}=3$ case of a tailless Pneumatic Channel Wing without outboard wing. At $\mathrm{C} \mu=0$, moving the $\mathrm{cg}$ aft from $\mathrm{x} / \mathrm{c}=0.25$ to 0.375 gives the aircraft neutral longitudinal stability but does produce trim over most of the angle of attack range. Similar reduction in pitching moment can be produced by aft $\mathrm{cg}$ shift as blowing is increased (Figure 19b), but this requires further aft $\mathrm{cg}$ to trim at lower $\alpha$, and the $C_{L} v C_{M}$ curves are now unstable $\left(\mathrm{dC}_{\mathrm{M}} / \mathrm{dC}_{\mathrm{L}}=+\right)$. Some small control surface (such as a blown canard to provide nose-up pitch and positive lift to trim) could perhaps be incorporated with a state-of-the-art control system and control laws to make this a feasible pitch-trim device without lift loss due to tail download.

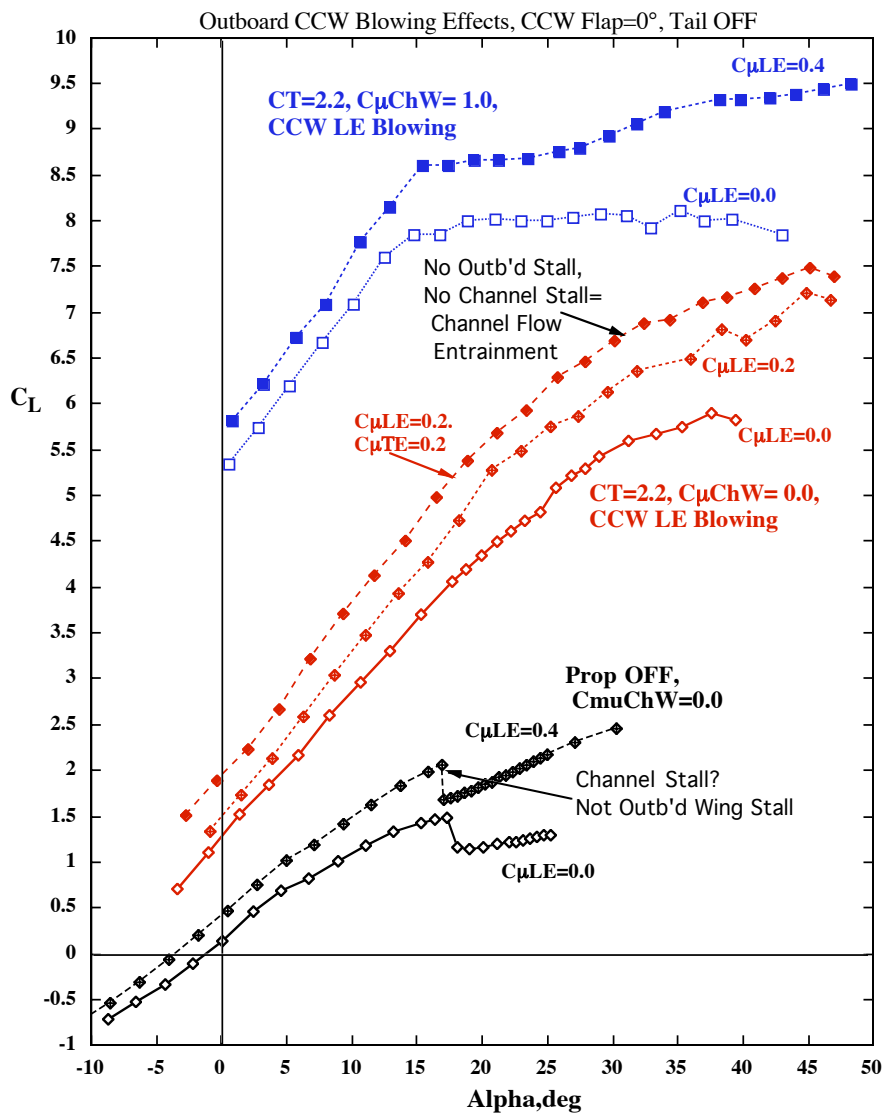

Figure 17 - Leading-edge Blowing and Channel Flow Entrainment Prevent Flow Separation over Both Channel and Outboard CCW Leading Edges 


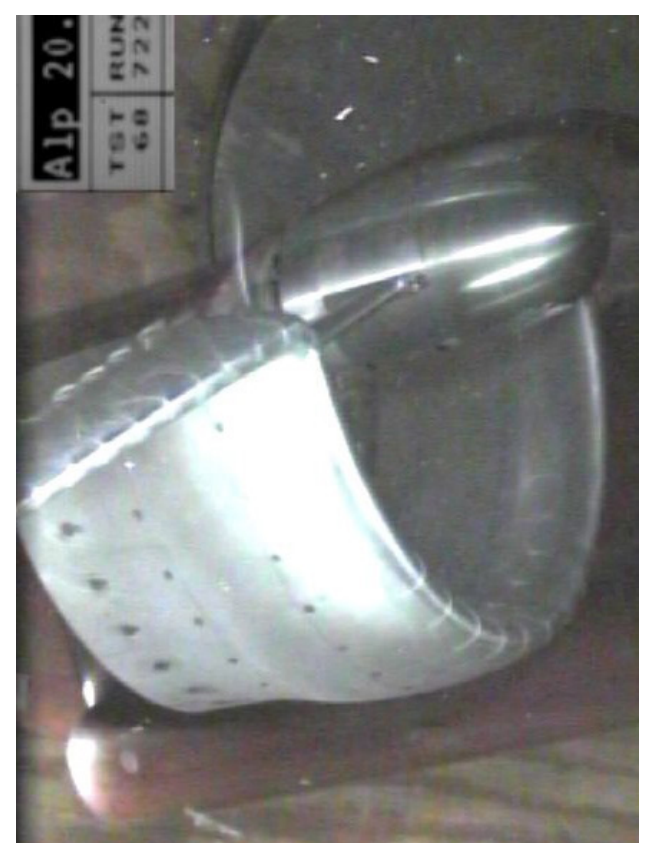

(a) Outboard LE slot unblown

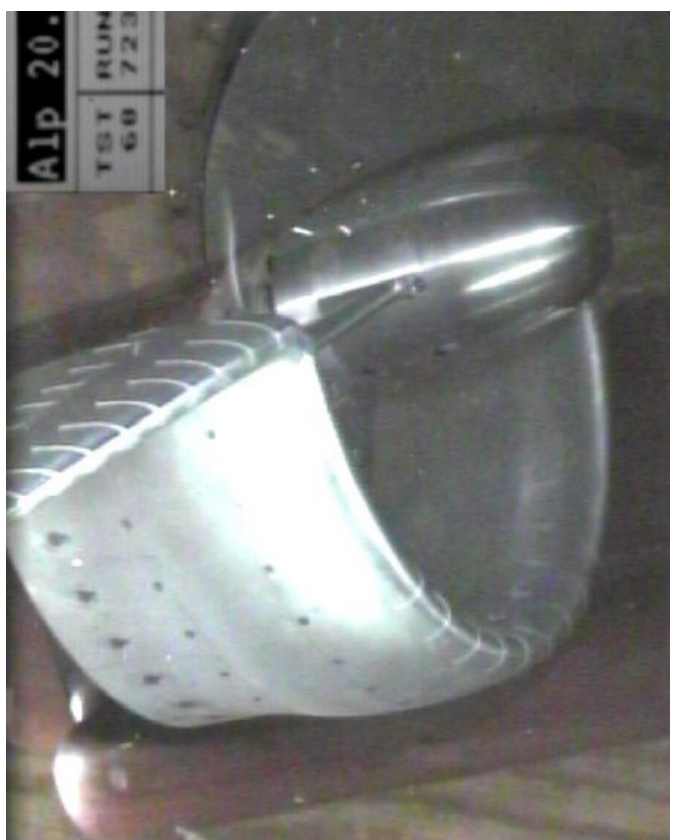

(b) Outboard LE Slot blown

Figure 18 - Flow Attachment Caused by Leading-edge Blowing on Outboard CCW and Channel Flow Entrainment at $\alpha=20^{\circ}$, Channel LE not Blown

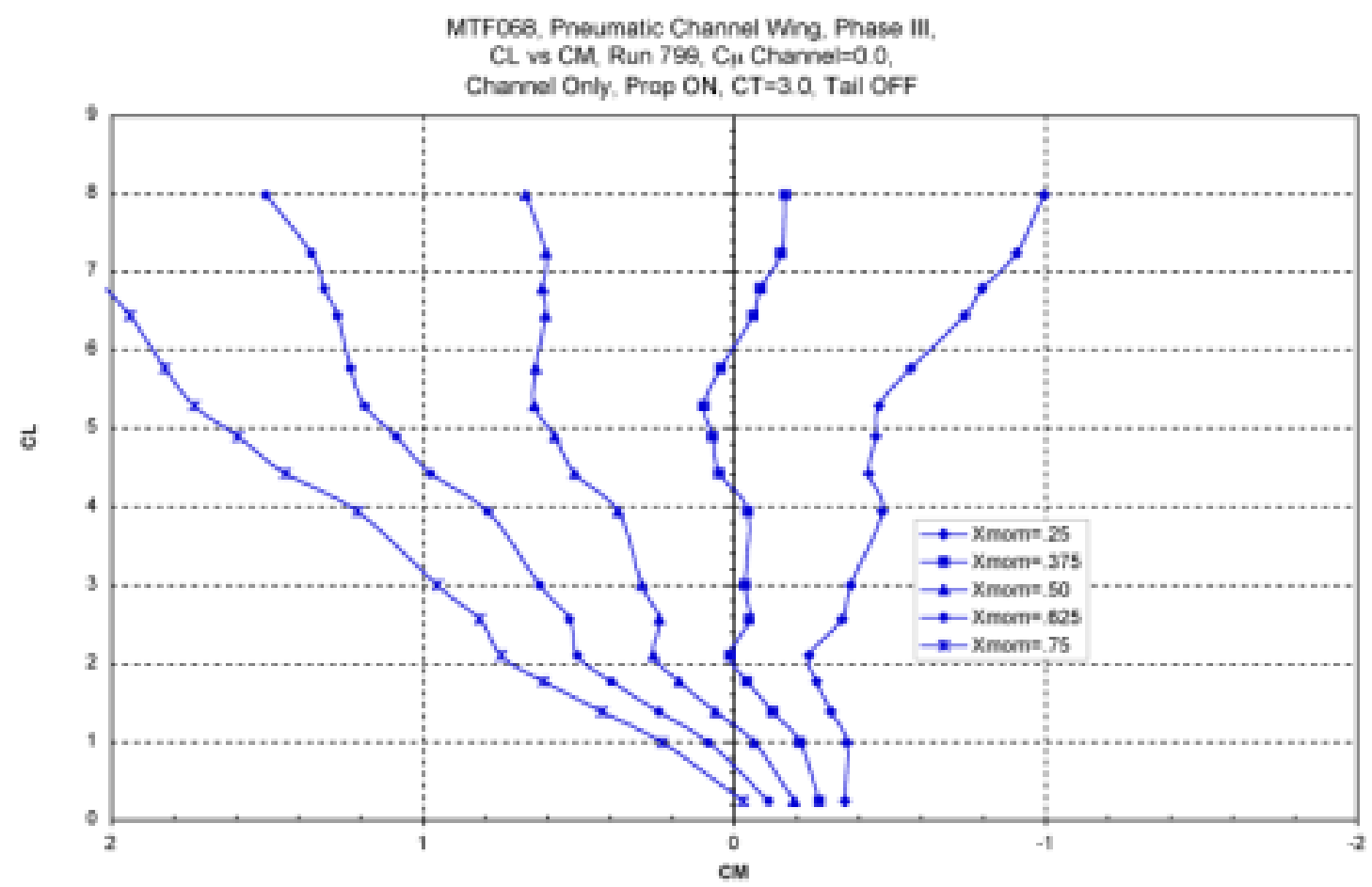

Fig. 19 (a) $C_{T}=3, C \mu=0$ 


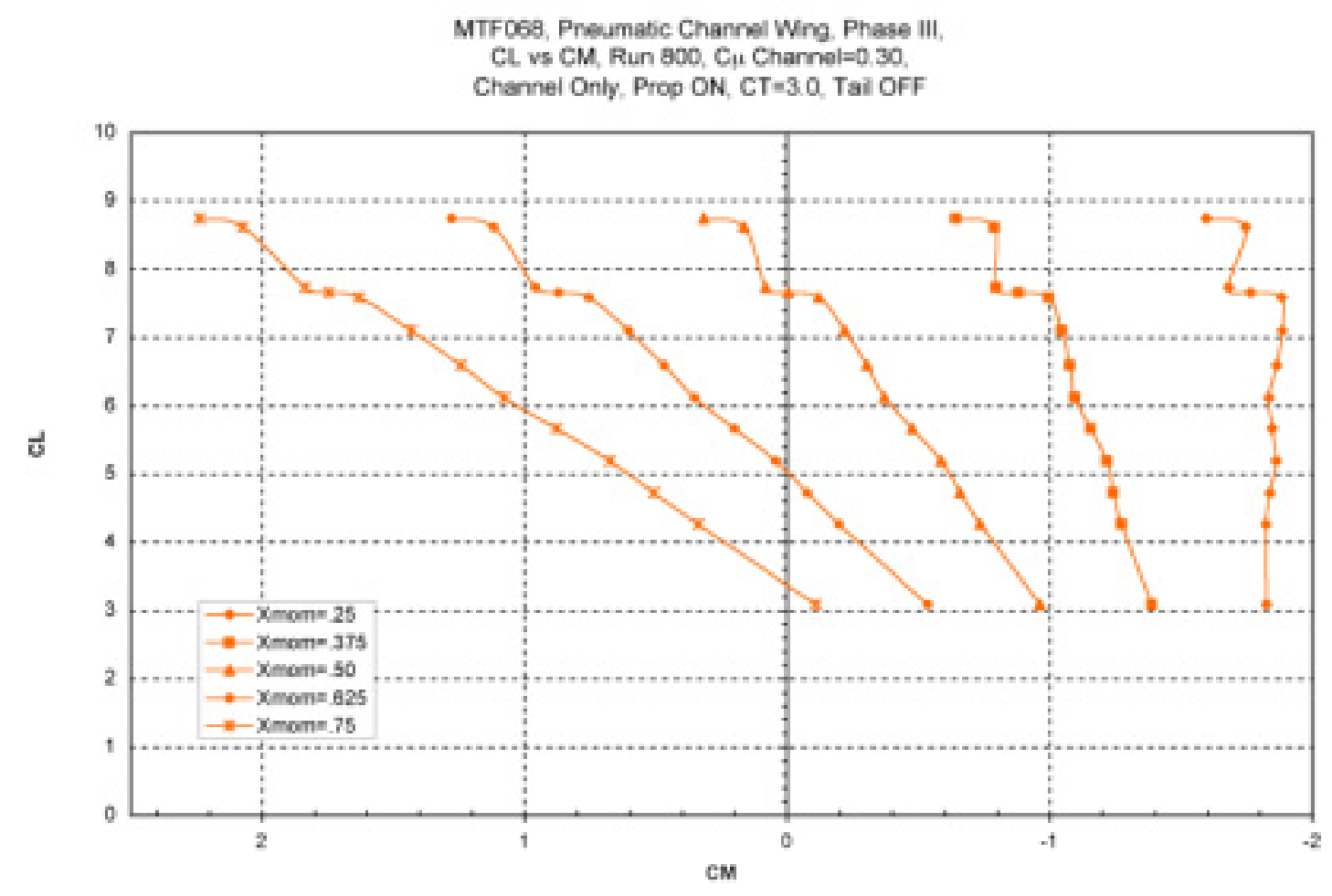

Fig. 19 (b) $\mathrm{C}_{\mathrm{T}}=3, \mathrm{C} \mu=0.3$

Figure 19 - Effect of Aft CG Location on Pitching Moment Curves for the Tail-less Pneumatic Channel Wing at $\mathrm{C}_{\mathrm{T}}=3, \quad \mathrm{Xmom}_{\mathrm{m}} \mathrm{X}_{\mathrm{cg}} / \mathrm{c}$

\section{Comparison of Measurements and Predictions}

In Figure 20 are compared the results of these investigations with previouslypredicted lift and drag data which were estimated from existing CCW/USB wind-tunnel data and from $A-6 / C C W$ flight-test data. Whereas the prop/electric motor currently available did not allow higher $\mathrm{C}_{T}$ values than about 2.2 (outboard wing $\mathrm{ON}$ ), this lower-thrust wind-tunnel data considerably surpasses the predicted lift data (Fig. 20a). If the ratio of measured-topredicted holds linearly up to $C_{T}=10$, then $C_{L}$ values over 14 are to be expected at $\alpha=10^{\circ}$. The experimental drag data (Fig. 20b) is similar to the predicted values at lower $\mathrm{C}_{\mu}$ but shows less drag than predicted at higher blowing. These estimated data had been used to predict Super-STOL takeoff distances on a hot day at $3000 \mathrm{ft}$ altitude to be less than 100 feet and in some instances, zero feet (see Reference 9 and Fig. 21 below). The measuredversus-predicted results in Figure 20 seem to suggest than even better takeoff performance might be obtained (higher lift, lower drag). However, the lower measured drag values indicate that additional attention will need to be paid to obtaining greater drag values for steeper glide slopes on STOL approaches (when desired and chosen by the pilot). 


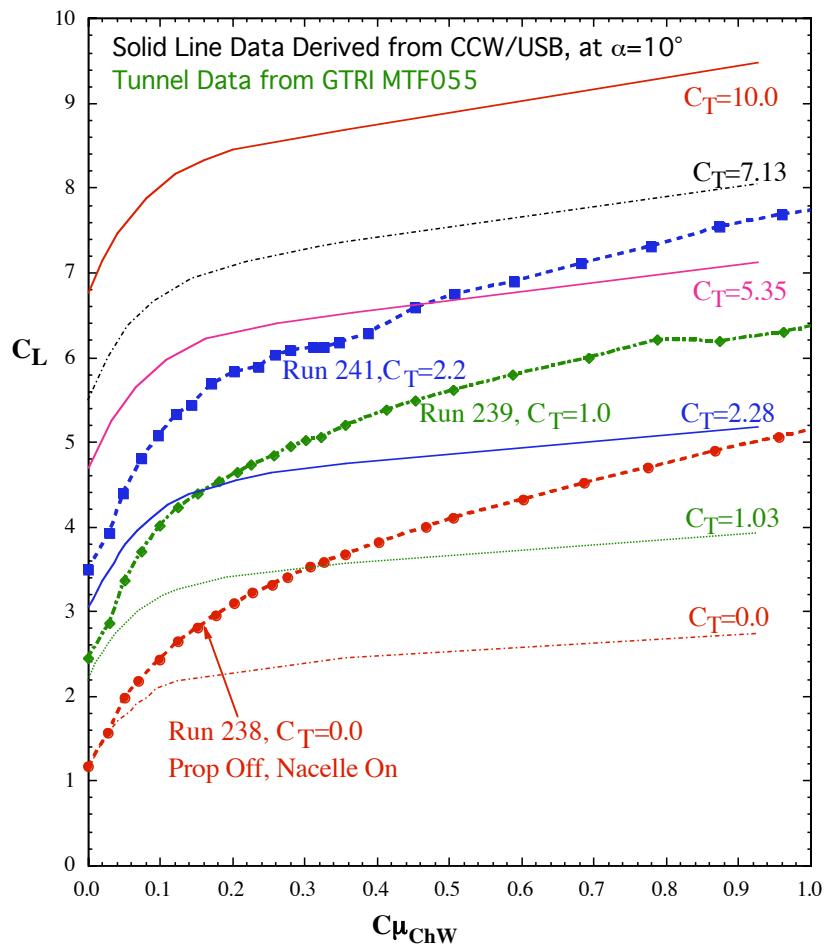

a. Measured vs Predicted Lift (symbols) (no symbols)

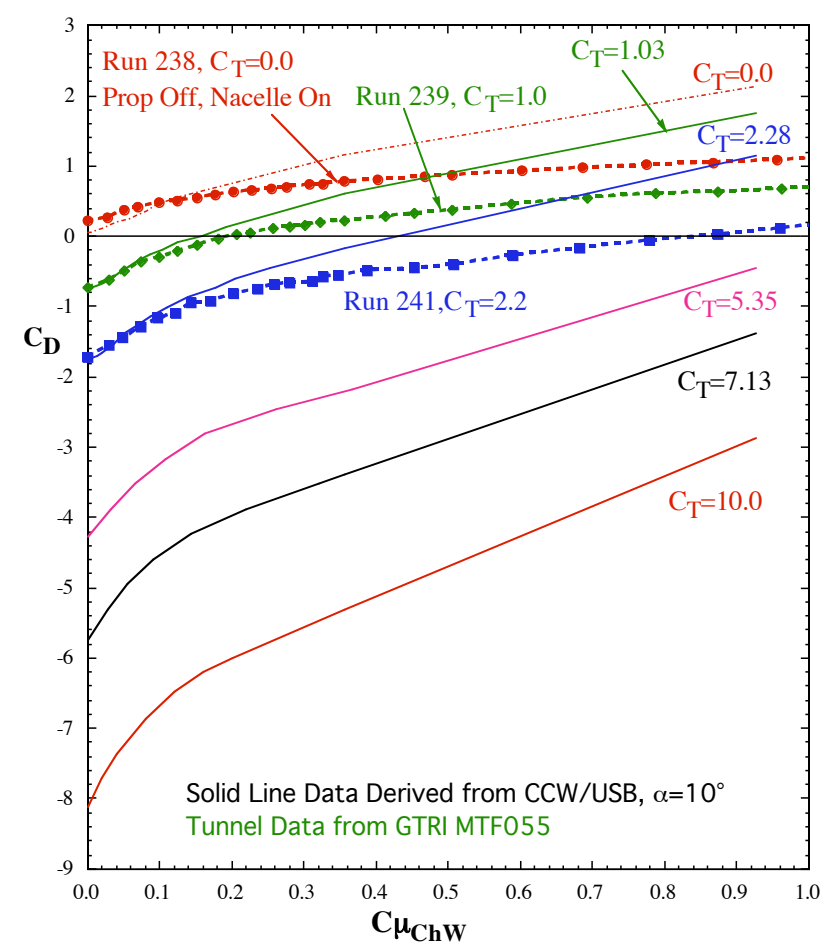

b. Measured vs Predicted Drag

Fig. 20 - Comparisons of Predicted and Experimental PCW Lift \& Drag Data at Constant $\mathrm{C}_{\mathrm{T}}$, $\alpha=10^{\circ}$,Outboard CCW ON
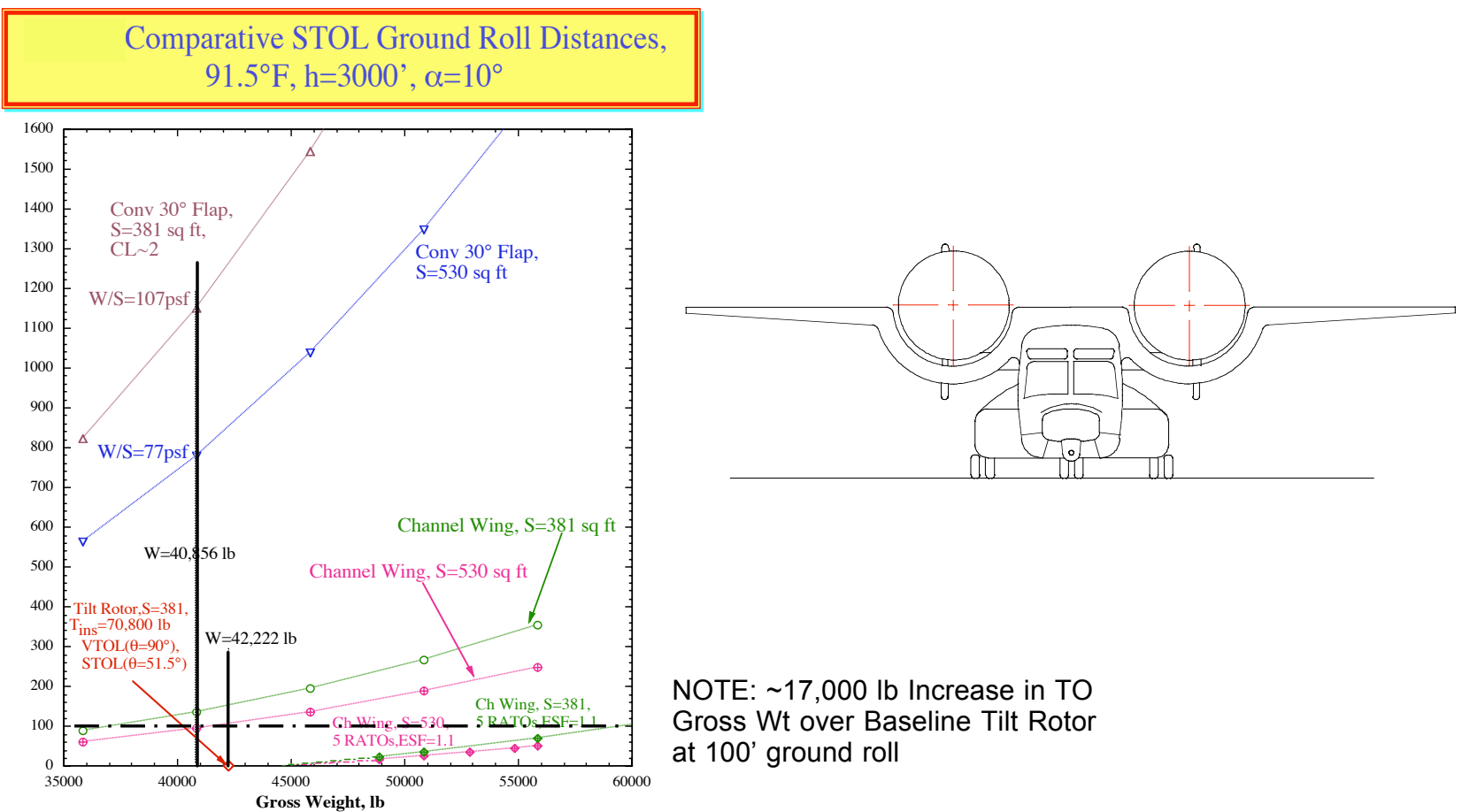

Fig. 21- Pneumatic Channel Wing Predicted Super-STOL Takeoff Performance 


\section{Potential Applications}

Design and mission studies conducted at NASA LaRC based on the above tunnel data have lead to consideration of several new pneumatic powered-lift PCW-type configurations. The capability of the Pneumatic Channel Wing to significantly augment lift, drag, and stall angle to the levels reported herein demonstrates that this technology has the potential to enable simple/reliable/effective STOL and possibly VTOL operations of personal and business-sized aircraft operating from remote or small sites as well as increasingly dense urban environments. Such capability now opens the way for alternate visions regarding civilian travel scenarios, as well as both civilian and military aerial missions. One such vision is represented by the Personal Air Vehicle Exploration (PAVE) activity at NASA Langley Research Center. Another vision, a military Super-STOL transport, is discussed in the mission study of Reference 9 and Figure 21 above.

\section{Summary and Conclusions}

Results from subsonic wind-tunnel investigations conducted at GTRI on a 0.075 scale powered semi-span model of a conceptual Pneumatic Channel Wing (PCW) transport have confirmed the potential aerodynamic payoffs of this possible Super-STOL configuration, including very high lift and overload capability. These results include:

- Lift and drag augmentations and/or reductions as desired for Super-STOL operation have been confirmed, with $C_{L}=9$ measured at $\alpha=10^{\circ}\left(C_{L}=10-11\right.$ at higher $\left.\alpha\right)$, and drag coefficient (including thrust) varying between -2 and +2 , depending on blowing and thrust levels. $\mathrm{C}_{\mathrm{L}}$ 's nearing 14 are predicted if higher $\mathrm{C}_{\mathrm{T}}$ is available, say on takeoff

- Blowing $(\mathrm{C} \mu)$ and thrust $\left(\mathrm{C}_{\mathrm{T}}\right)$ variations were both found to significantly enhance circulation, thrust deflection and lift; but, if evaluated as incremental lift per unit of input thrust or momentum $\left(\mathrm{C}_{\mathrm{T}}\right.$ or $\left.\mathrm{C} \mu\right)$, blowing was far more efficient than thrust.

- By varying only $\mathrm{C} \mu$ and/or $\mathrm{C}_{\mathrm{T}}$, all the aircraft's aerodynamic characteristics (forces and moments) can be augmented or reduced as desired by the Super-STOL aircraft's pilot or it's control system without mechanical moving parts (such as tilting rotors or wings) and without resorting to high $\alpha$ to acquire larger vertical thrust components for lift.

- The blown channel wing itself, without thrust applied, was able to double the CLmax capability of the baseline aircraft configuration, and multiply its lift at $\alpha=0^{\circ}$ by a factor of 10 . Addition of blowing on the outboard CCW section can increase this further, and can also add drag as needed for Super-STOL approaches.

- Even with the unblown outboard wing stalling at $\alpha=15^{\circ}-17^{\circ}$, the blown and thrusting channel continued to increase lift up to a stall angle of $40^{\circ}-45^{\circ}$ due to channel flow entrainment. While this high $\alpha$ may not prove practical as a takeoff/landing operational incidence, it does show significant improvement over the asymmetric LE separation of 
the conventional channel wing's stalled channel and the resulting low-speed control problems.

- PCW conversion of thrust into either drag decrease or drag increase without moving parts is also quite promising for STOL operation.

- Large nose-down pitching moments are produced by these blown configurations, and thus longitudinal trim capability needs to be addressed in future evaluations.

- Unlike a tilt rotor, in Super-STOL or VSTOL, there is no download on the wing from prop thrust since the PCW props don't tilt

- PCW's potential for an integrated lift, thrust/drag interchange and control system all from one set of devices holds promise in terms of simplity, weight reduction and reliability/maintainability

Thus far, the projected operational benefits based on these early data suggest SuperSTOL and possible VSTOL capability with significantly increased payload, reduced noise signatures, and increased engine-out control, all without variable geometry or mechanical engine/prop tilting. A Pneumatic Channel Wing aircraft thus equipped could provide a simpler, less costly way of achieving the Super-STOL/VSTOL capability without the complexity, weight or reliability issues of rotating the propulsion system, carrying large engines and rotors on the wing tips, or thrusting downwards on fixed wings during hover. Additionally, the integration of pulsed-blowing technology with Circulation Control (currently being investigated by GTRI and NASA, Ref. 12) may further increase lift efficiency and reduce already low blowing requirements by up to $50 \%$ or more, while further enhancing stability and control. Successful application of these results can lead to positive technology transfer to personal, business, and military sized aircraft. In addition to the military Super-STOL transport discussed above, NASA LaRC has included these experimental data and pneumatic technology results in preliminary design studies of other possible pneumatic powered-lift configurations, including smaller personal and business-type aircraft

\section{$\underline{\text { Recommendations }}$}

Future testing, evaluation and development still need to be accomplished to address possible pitch-trim problems, performance at higher $\mathrm{C}_{T}$ and lower $\mathrm{C}_{\mu}$, and associated stability and control. In the future, the existing model or larger 3-D models should be modified to include blown tail surfaces and additional improvements to the pneumatic thrust deflection system. The following should be experimentally investigated:

- Use of pulsed blowing to further reduce required blowing mass flows (both inboard on the channel and outboard on the CCW).

- Higher propulsor solidity for greater thrust and powered lift, or improved propeller characteristics for greater $\mathrm{C}_{\mathrm{T}}$ availability. 
- Further evaluation of low-speed controllability and trim, including evaluation of improved tail surfaces, which might even be blown to reduce tail area and drag.

- Further evaluation of low-speed controllability and trim by novel aerodynamic/ pneumatic trim and control devices (blown canards, for example.)

The earlier mission analyses should be revised to incorporate the experimentally developed aeropropulsive and stability \& control characteristics of the Pneumatic Channel Wing concept. If the projected benefits are confirmed, and further benefits come to light, then larger-scale, higher-Reynolds-number testing on a full-3-D Pneumatic Channel Wing model with variable yaw capability should be conducted to facilitate greater strides toward this pneumatic powered-lift technology's maturation .

\section{References}

1. Pasamanick, Jerome, "Langley Full-Scale-Tunnel Tests of the Custer Channel Wing Airplane," NACA RM L53A09, National Advisory Committee for Aeronautics, April 1953.

2. Mitchell, Kent A., "Mr. Custer and His Channel Wing Airplanes," Journal of American Aviation Historical Society, Spring 1998.

3. Blick, Edward. F, and Vincent Homer, "Power-on Channel Wing Aerodynamics," AIAA Journal of Aircraft, Vol. 8, No. 4, pp. 234-238, April 1971.

4. Englar, Robert J., "Circulation Control Pneumatic Aerodynamics: Blown Force and Moment Augmentation and Modification; Past, Present and Future," AIAA Paper 20002541, AIAA Fluids 2000 Meeting, Denver, CO, June 19-22, 2000.

5. Englar, R. J. and C. A. Applegate, "Circulation Control - A Bibliography of DTNSRDC Research and Selected Outside References (Jan. 1969 through Dec. 1983)," DTNSRDC84/052, September 1984.

6. Englar, R. J., "Development of Circulation Control Technology for Powered-Lift STOL Aircraft," NASA CP-2432, "Proceedings of the 1986 Circulation Control Workshop".

7. Englar, R. J., J. H. Nichols, Jr., M. J. Harris, J. C. Eppel, and M. D. Shovlin, "Development of Pneumatic Thrust-Deflecting Powered-Lift Systems," AIAA Paper No. 86-0476, AIAA 24th Aerospace Sciences Meeting, Reno, Nevada, January 6-9, 1986.

8. Pugliese, A. J. (Grumman Aerospace Corporation) and R. J. Englar (DTNSRDC), "Flight Testing the Circulation Control Wing," AIAA Paper No. 79-1791, AIAA Aircraft Systems and Technology Meeting, August 1979.

9. Hines, N., A. Baker, M. Cartagena, M. Largent, J. Tai, S. Qiu, N. Yiakas, J. Zentner and R. J. Englar, "Pneumatic Channel Wing Comparative Mission Analysis and Design Study, Phase I," GTRI Technical Report, Project A-5942, March 22, 2000. 
10. Englar, R. J. and R.M. Williams, "Test Techniques for High Lift Airfoils with Boundary Layer and Circulation Control for Application to Rotary Wing Aircraft," Canadian Aeronautics and Space Journal, Vol. 19, No. 3, pp. 93-108, March, 1973.

11. Englar, R. J., Niebur, C. S., and Gregory, S. D., "Pneumatic Lift and Control Surface Technology for High Speed Civil Transport Configurations," AIAA Journal of Aircraft, Vol. 36, No.2, pp. 332-339, March-April, 1999.

12. Jones, G. S., and R.J. Englar, "Advances in Pneumatic-Controlled High-Lift Systems Through Pulsed Blowing", AIAA 2003-3411, AIAA $21^{\text {st }}$ Applied Aerodynamics Conference, Orlando, June 23-26, 2003. 


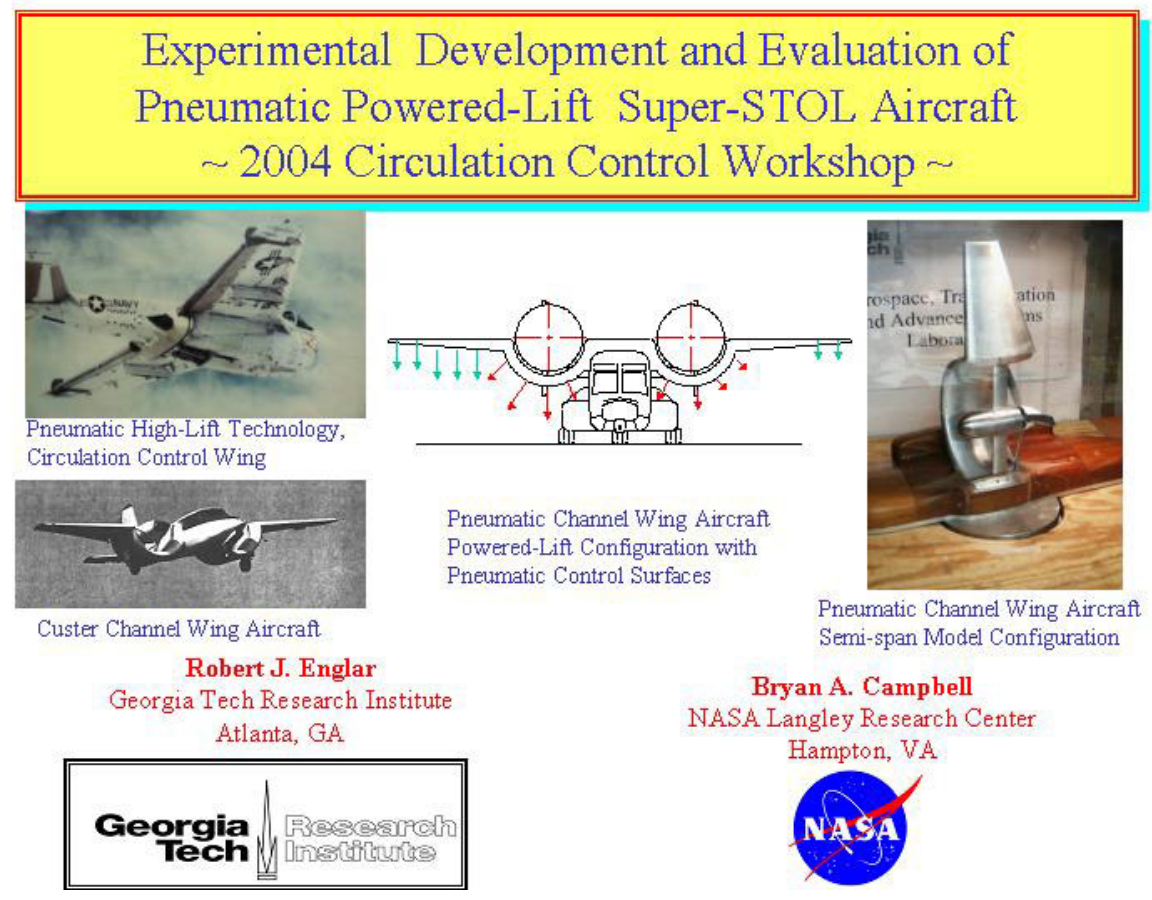

\section{Outline of Presentation}

- Introduction \& Background Custer Channel Wing Circulation Control Wing (CCW) CCW/Upper Surface Blowing

- Pneumatic Channel Wing Concept

- Current Pneumatic Channel Wing Configuration

- Test Apparatus, Models, Techniques and Setup

- Experimental Results

- $\underline{\text { SuperSTOL Performance }}$

- Predicted Payoffs and Benefits

- $\underline{\text { Summary and Conclusions }}$

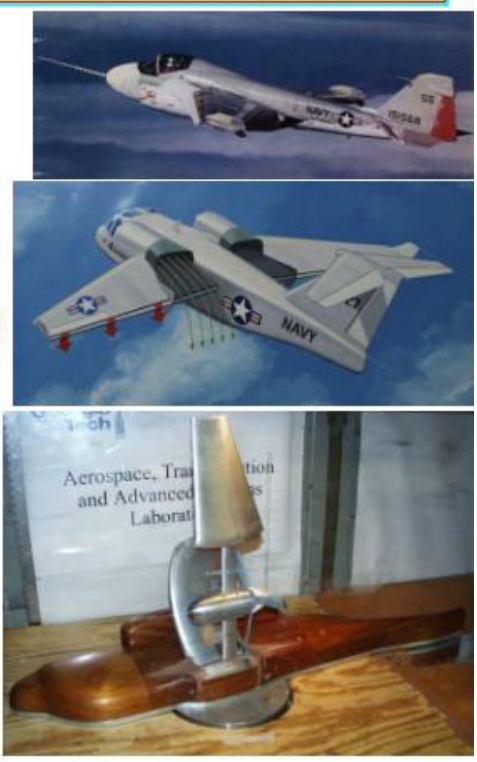




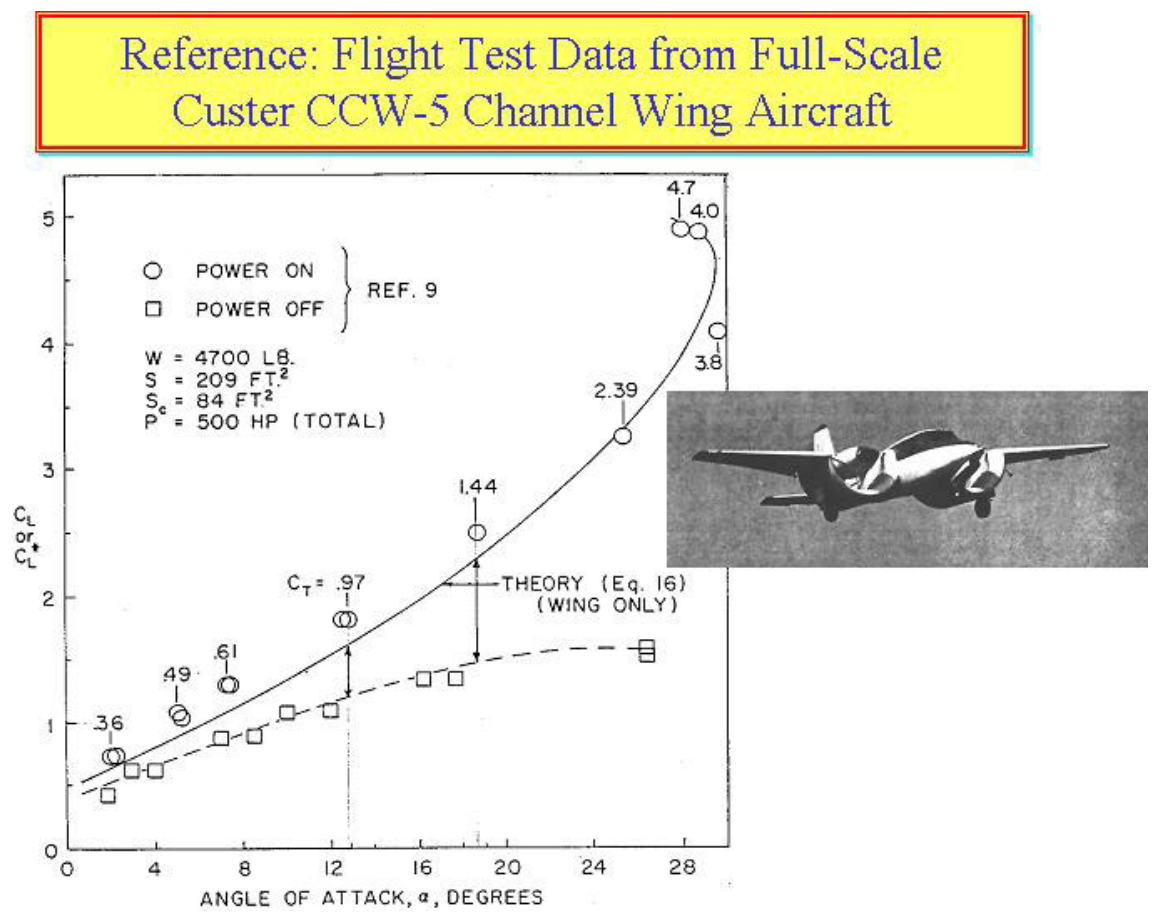

Disadvantages of Conventional Channel Wing Configuration

- Much of High $\mathrm{C}_{\mathrm{L}}$ is from Redirected Thrust, little augmentation

- High Drag from Channel Surface Area

- Asymmetric Thrust yields Asymmetric Moments \& Instability

- Channel Leading-edge and Trailing-edge Separation at High $\alpha$

- Poor low-speed control from conventional aerodynamic surfaces

- Nose-down Pitch from Aft Propeller

- Non-Uniform Flow around Prop at High $\alpha$

- Poor Lift/Drag ratio

- High angle of attack operation:poor visibility,control

- One-engine-out control problems
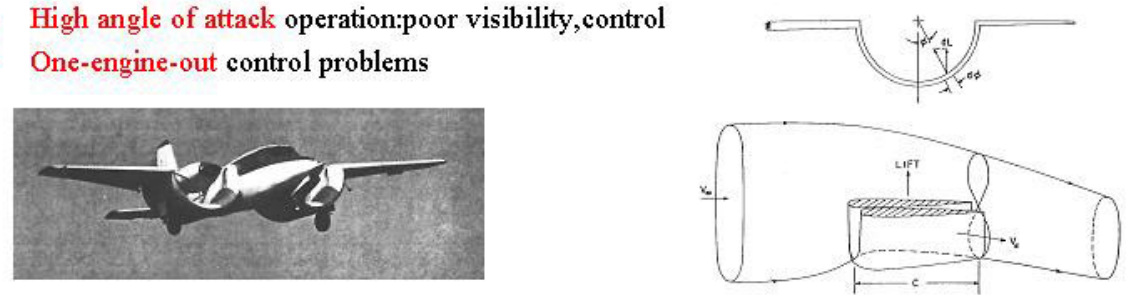

- ALL ARE SOLVABLE BY PNEUMATIC SYSTEMS APPLICATION, and ADDITIONAL SYNER GIES WILL RESULT 


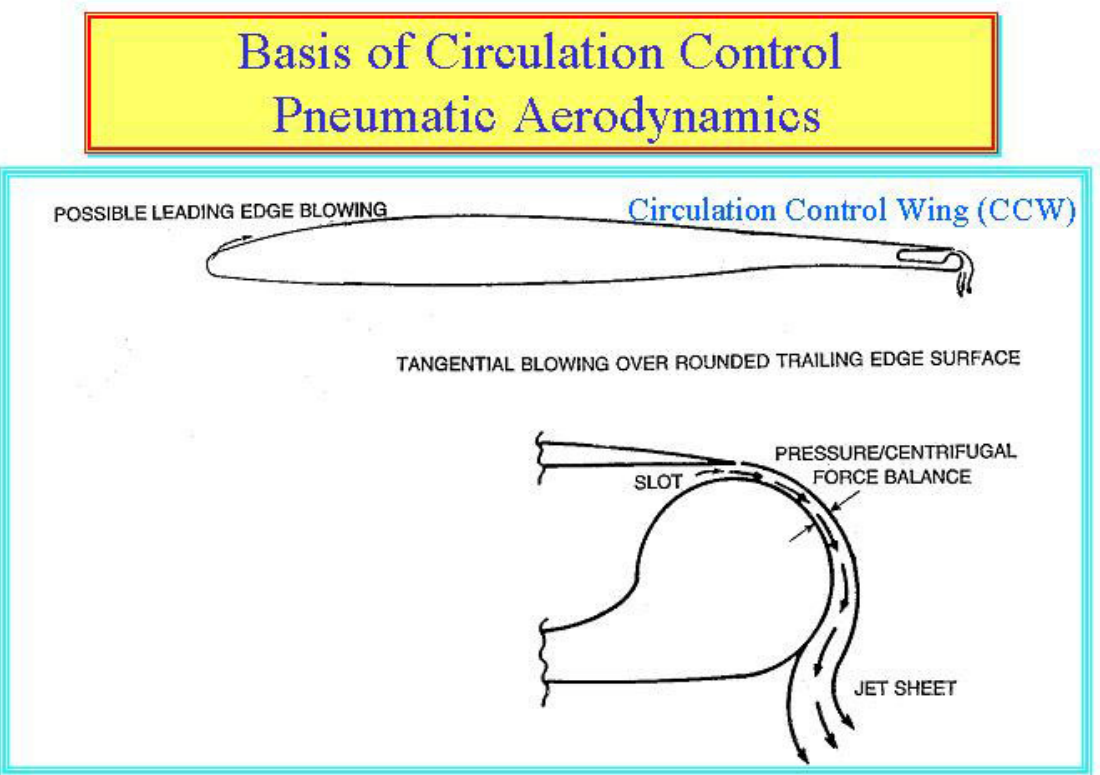

Basis for Outboard CCW and Inboard Pneumatic Channel Wing

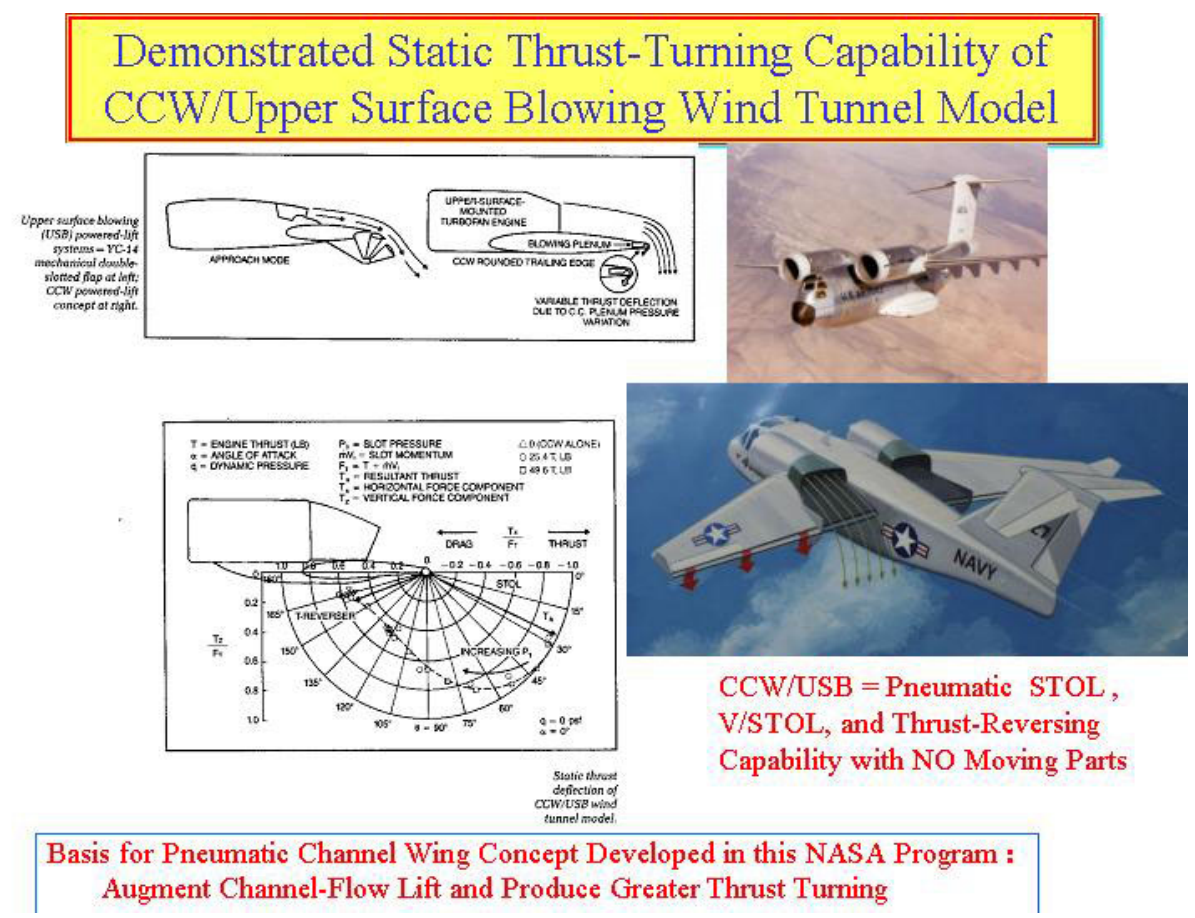


Basis of Channel Wing Propulsive Aerodynamics and Current Pneumatic Developments

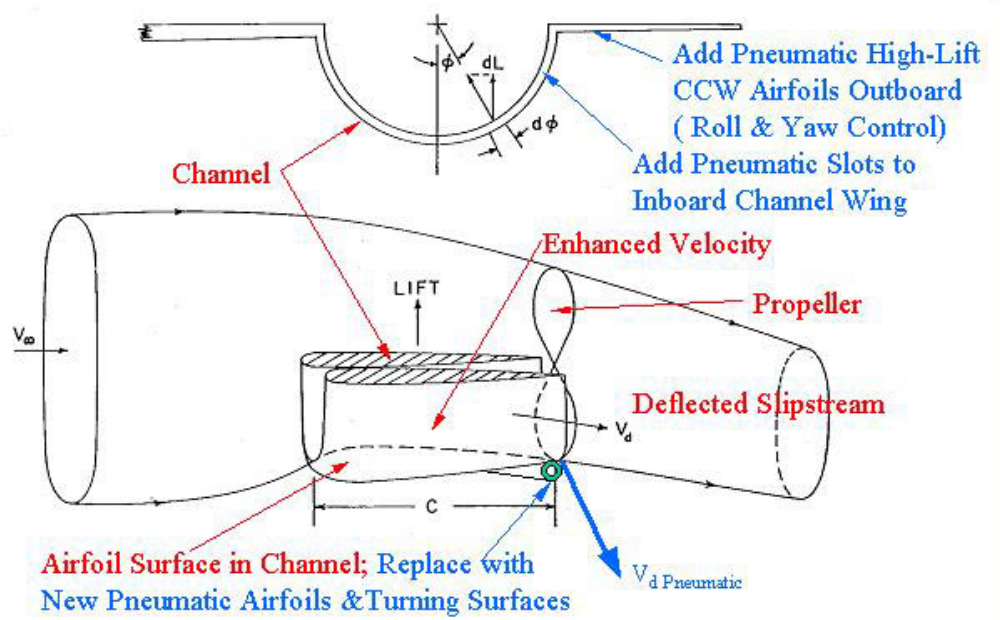

\begin{tabular}{|c|c|}
\hline Georgia \\
Tech \\
\hline
\end{tabular}

3D Channel Wing Configuration

\section{Technology Goal: Merging Custer Channel Wing and Circulation Control to provide simple, reliable and effective SuperSTOL (VSTOL) aircraft, with ample control} Operations: Remote or small sites, as well as increasingly dense urban environmentsMilitary, PAV and Commercial Applications

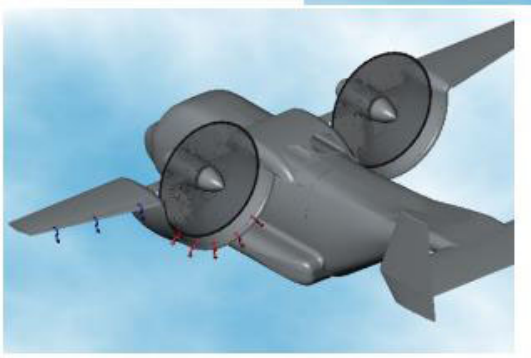




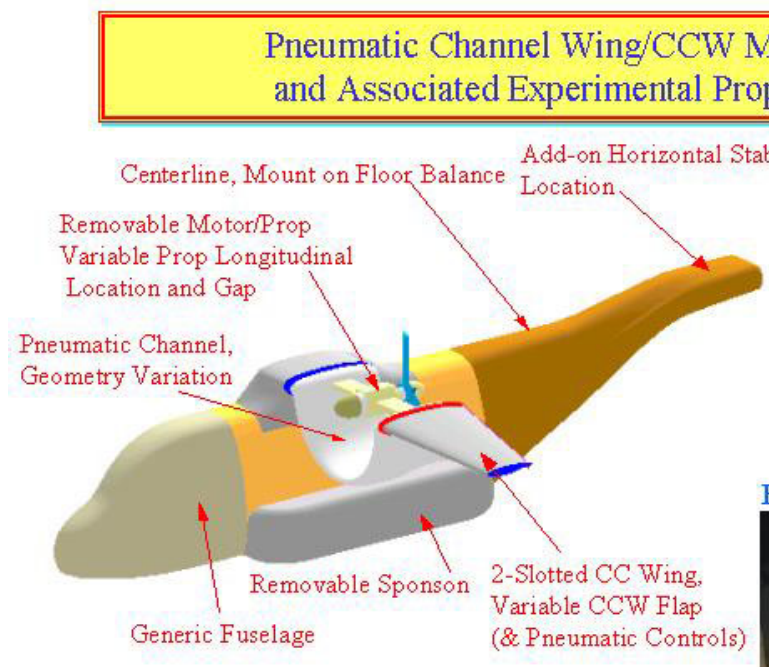

Half-span 0.075-scale Powered Pneumatic Channel Wing Model with 3 Air Supply Sources: Channel TE, Wing LE \& TE

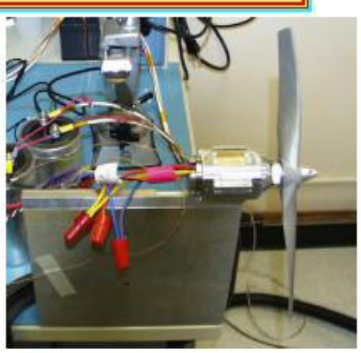

Electric Motor and Prop Cal Setup
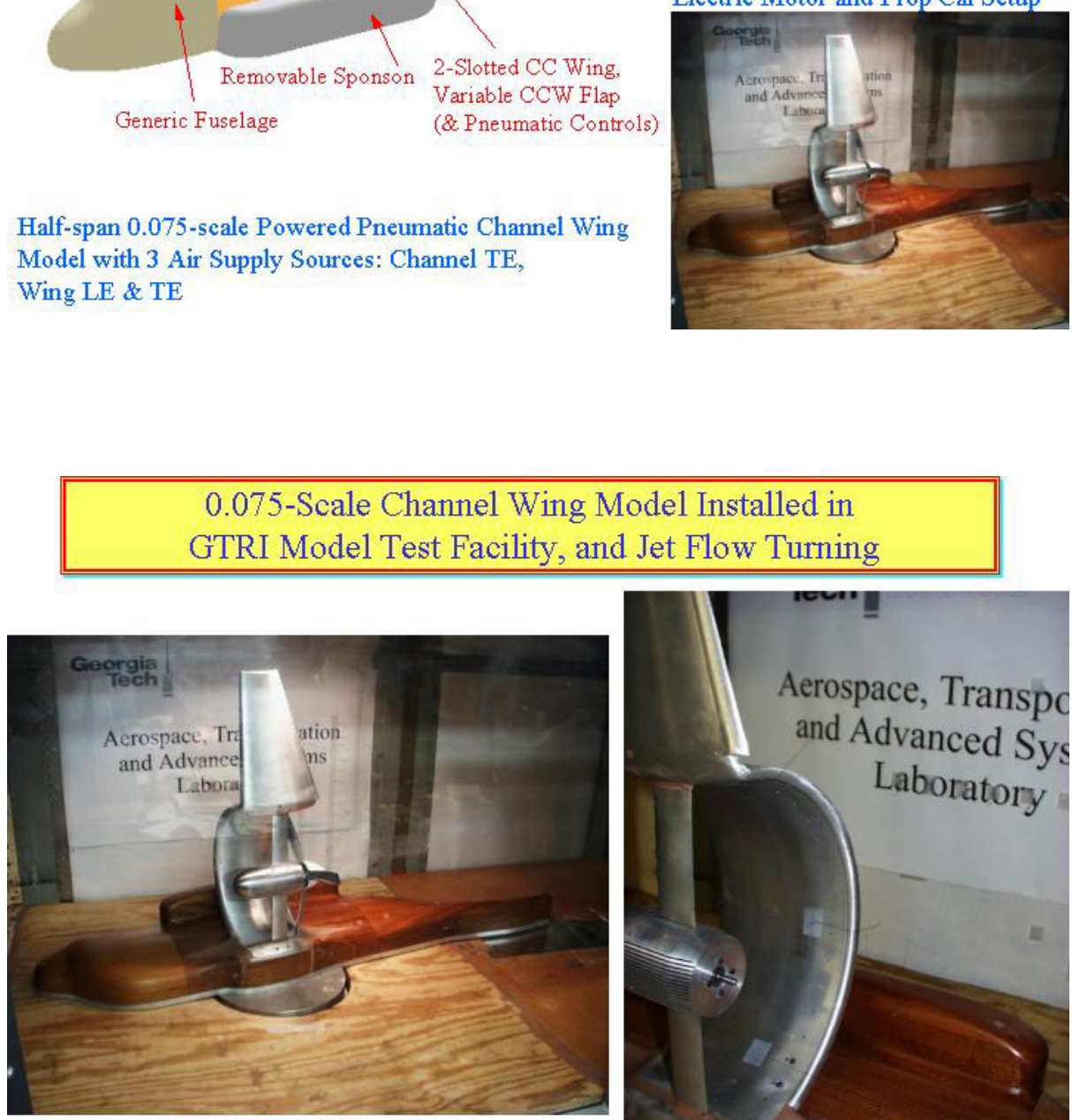

Semi-Span Pneumatic Model with Prop Installed at Aft Location

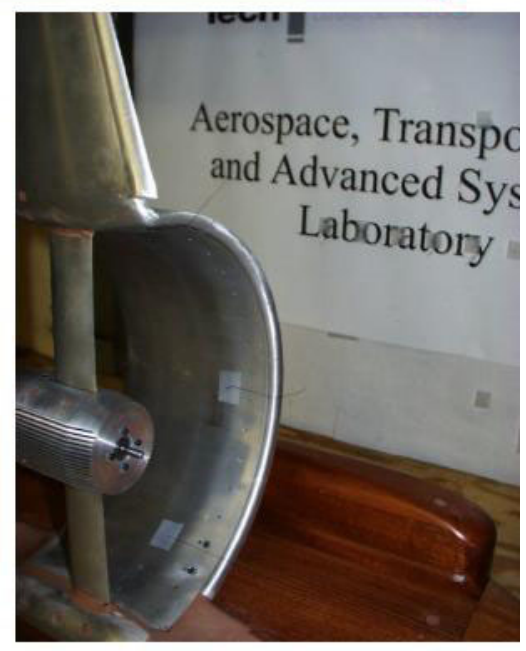

Assembled Pneumatic Channel with Blowing and Flow Turning 


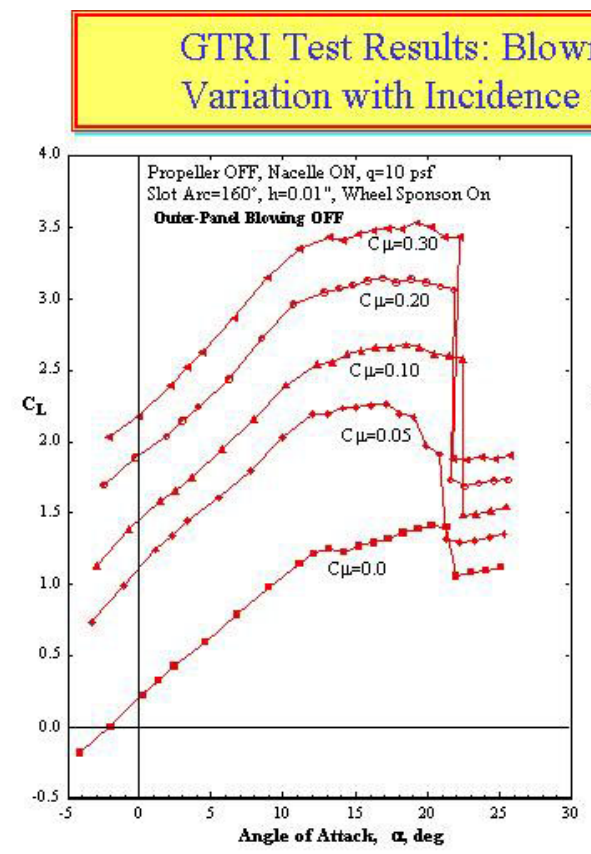

Lift Increase due to Channel Blowing

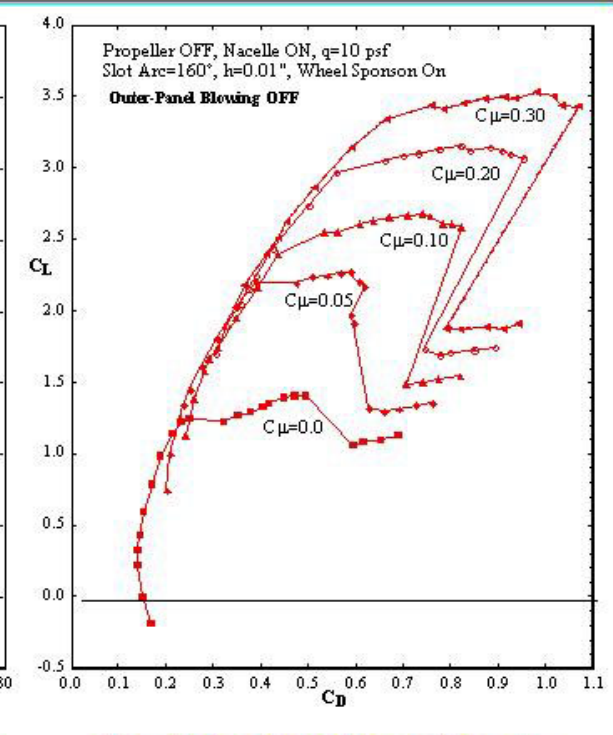

Drag Polars due to Channel Blowing

GTRI Proof-of-Concept Wind-Tunnel Test Results: Effects of Blowing $(\mathrm{C} \mu) \&$ Thrust $\left(\mathrm{C}_{\mathrm{T}}\right)$ Variation on Lift \& Drag

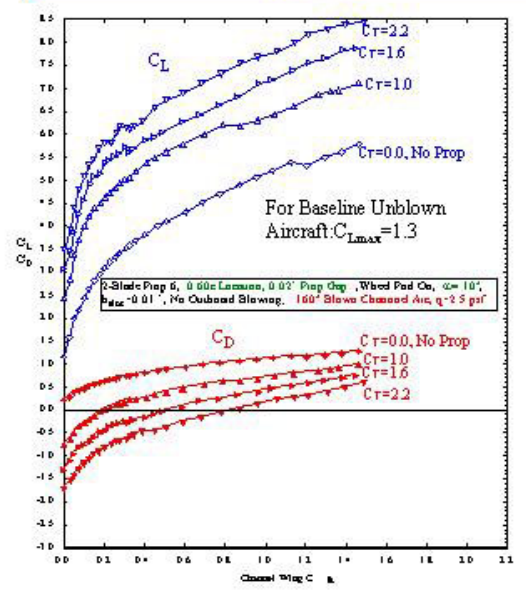

$\mathrm{C} \mu$ Variation: Note that Lift Augmentation from Blowing is much greater than linear in $\mathrm{C}_{\mu}$ $\mathrm{C}_{\mathrm{D}}$ varies with Blowing, Very Useful on STOL Approaches $\left(\alpha=10^{\circ}\right)$

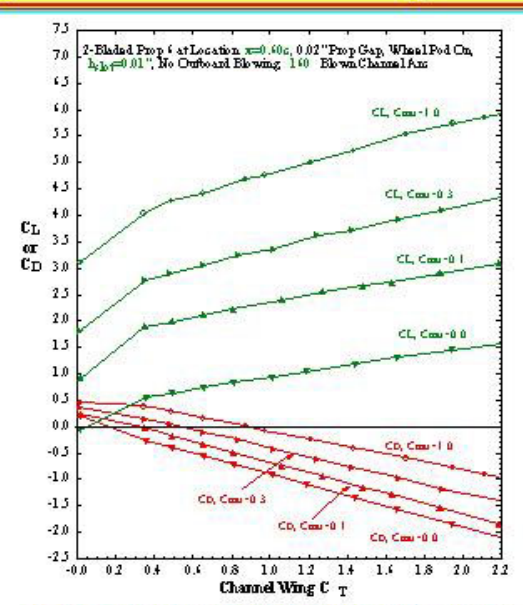

$\mathrm{C}_{\mathrm{T}}$ Variation: Note that Lift from Thrust is nearly linear in $C_{T}, C_{D}$ is mostly Thrust recovery \& Linear $\mathrm{C}_{\mathrm{D}}=\mathrm{C}_{\text {horizrtal }}$ includes horizontal $\mathrm{C}_{\mathrm{T}}$ component $\mathrm{C}_{\mathrm{T}}=\mathrm{T} /(\mathrm{qS})$, where $\mathrm{T}$ is calibrated thrust at test speed, $(\alpha=09)$ 


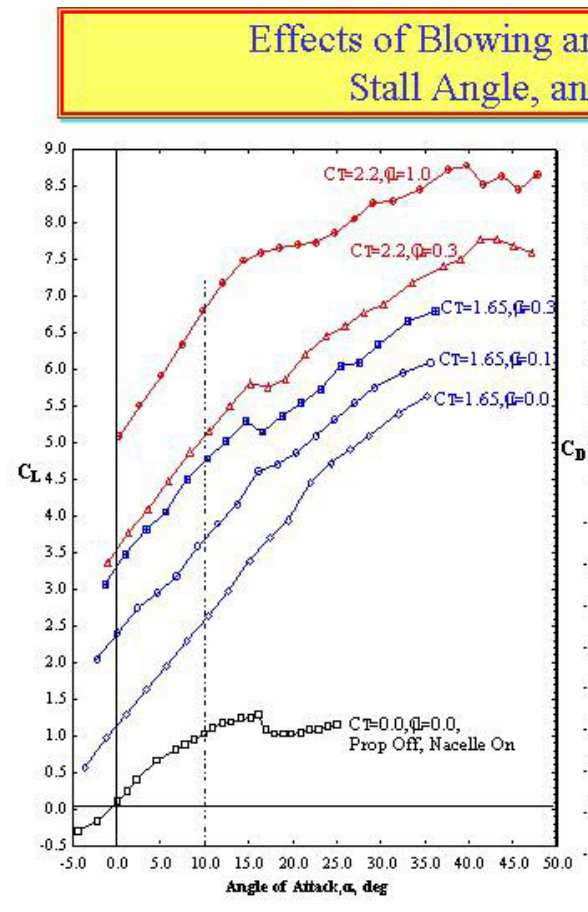

Effects of Blowing and $\mathrm{C}_{\mathrm{T}}$ on Lift Coefficient, Stall Angle, and Drag Coefficient

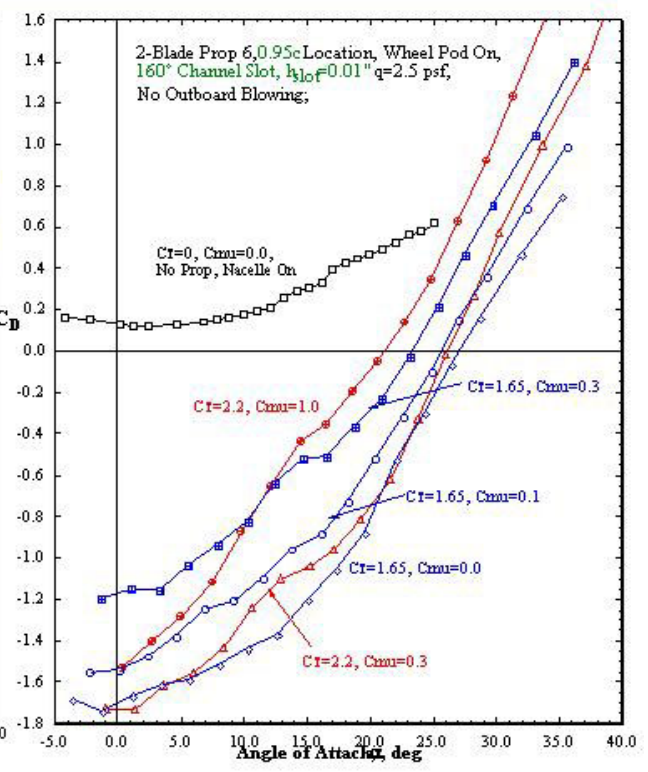

Addition of Outboard LE \& TE Blowing for Extra $C_{L}$ \& LE Flow Attachment, (Channel Thrust and Blowing Off)

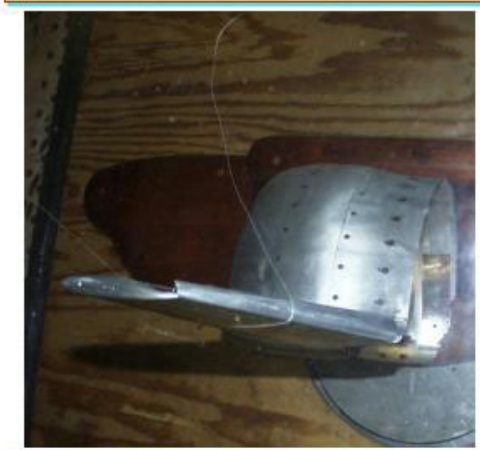

Outboard CCW Jet Turning, $90^{\circ}$ Flap to Yield Extra $\mathrm{C}_{\mathrm{L}}$ \& Control (Photo is inverted)

Outboard LE Blowing for LE

Flow Attachment through $\alpha=45^{\circ}$, Plus additional BL Entrainment And TE attachment

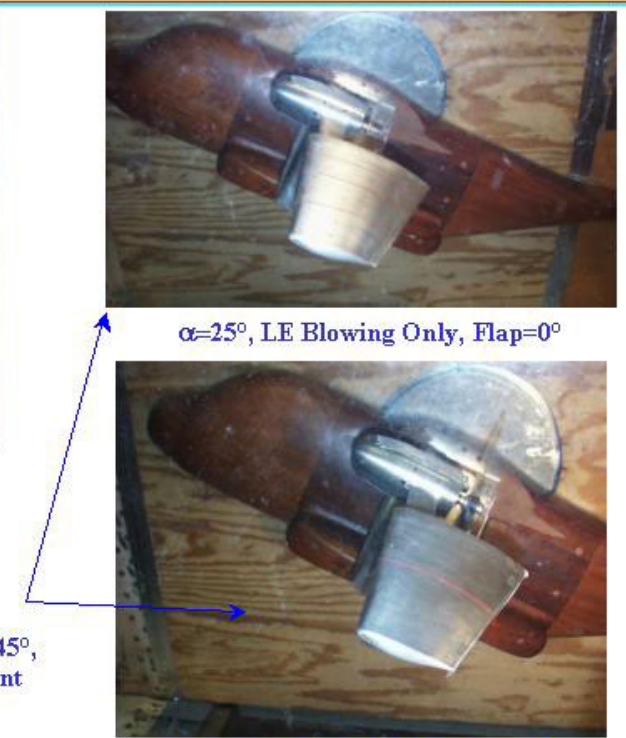

$\alpha=25^{\circ}$, LE Blowing Only, Flap $=90^{\circ}$ 


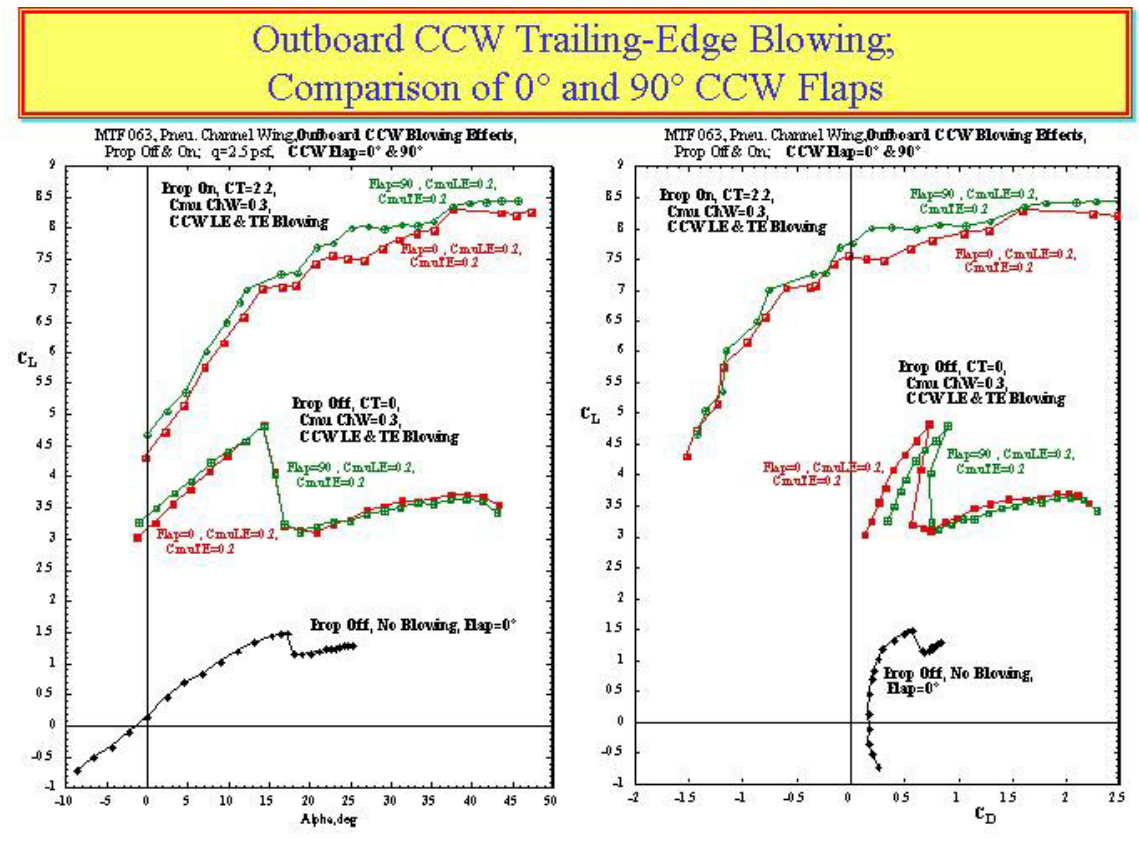

Flow Visualization showing Leading-Edge Separation at Higher Lift and $\alpha\left(\mathrm{C}_{\mathrm{T}}=2.2, \mathrm{C} \mu_{\text {channel }}=1.0, \mathrm{LE}\right.$ Blowing OFF $)$

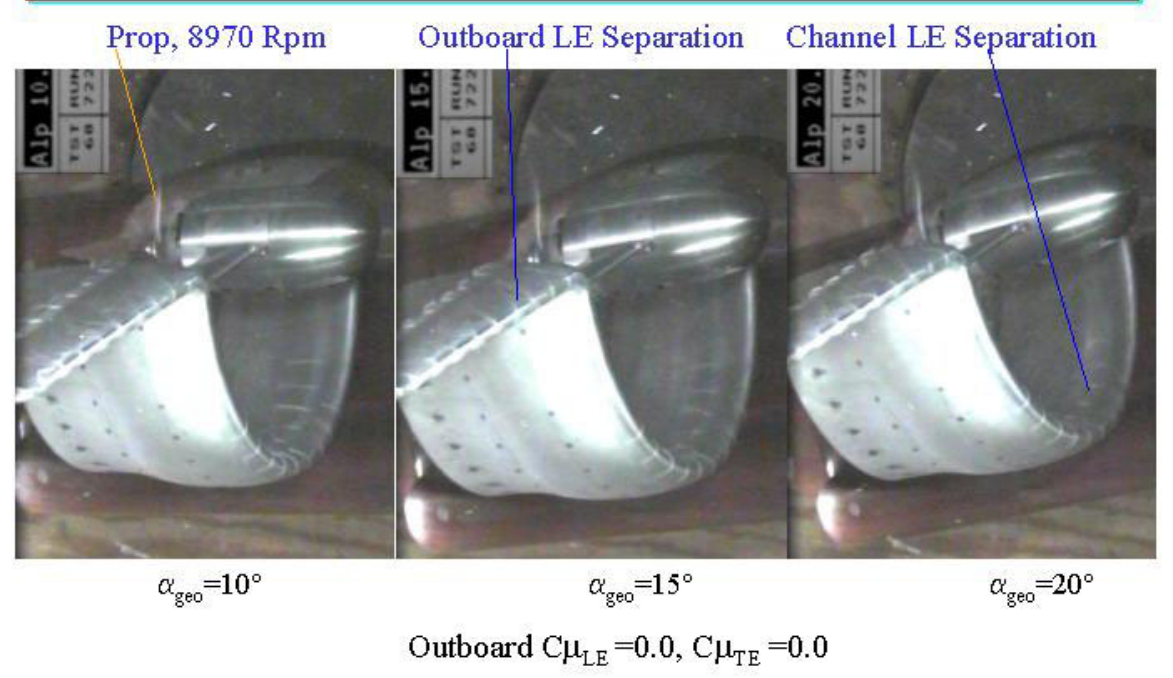

Tuft fuzziness or reversal indicates flow separation

(Video Still Frames, Video Available from GTRI) 


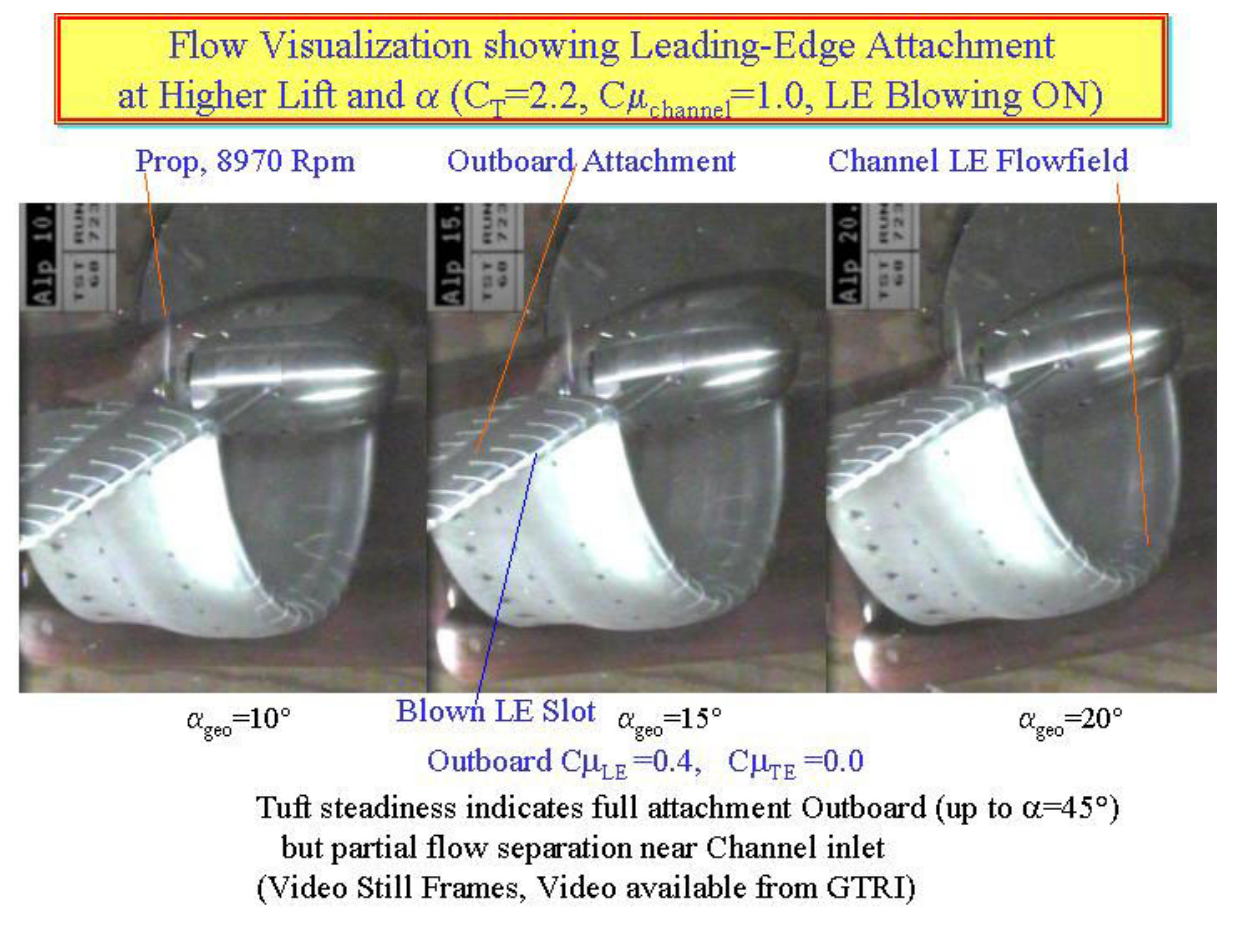

Leading-Edge Blowing Prevents LE Stall on Outboard CC Wing; Channel Flow Entrainment Allows Very High $\alpha$ and $\mathrm{C}_{\mathrm{I}}$
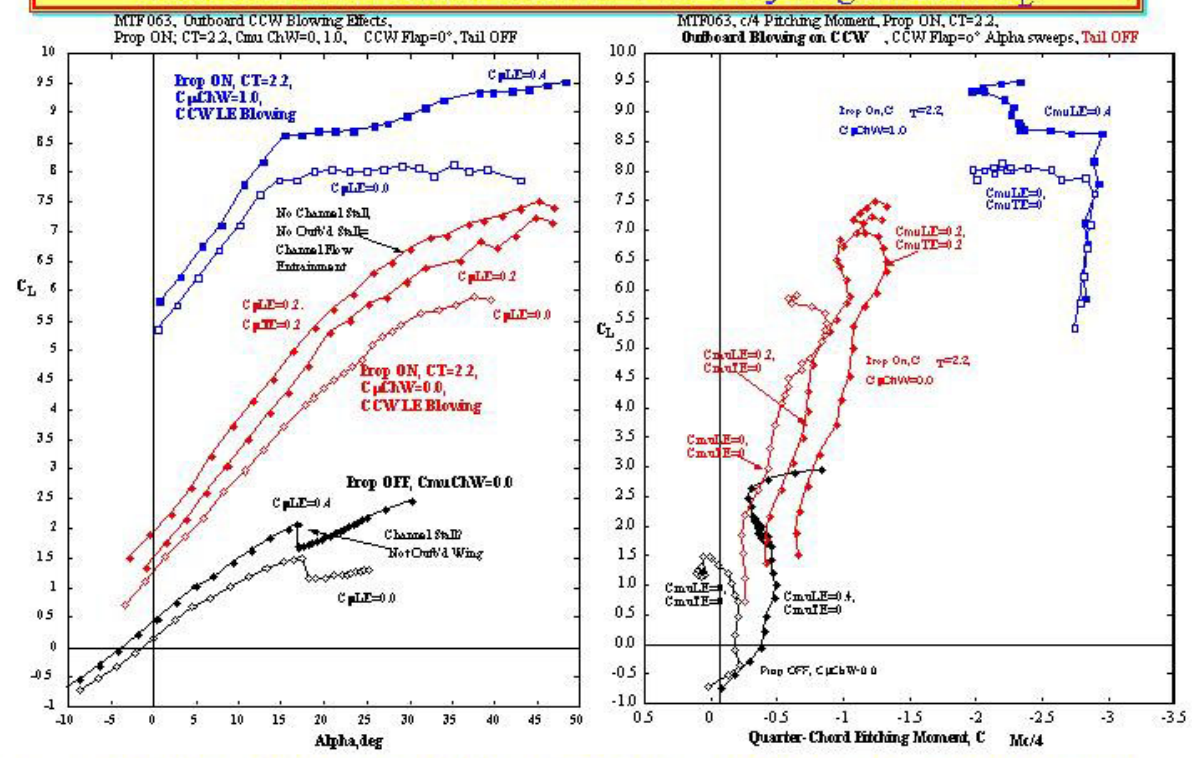

$\alpha_{\text {stall }}=45^{\circ}-50^{\circ}$ due to LE Blowing and Channel LE Entrainment; Stable, but $C_{M}$ must be Trimmed 


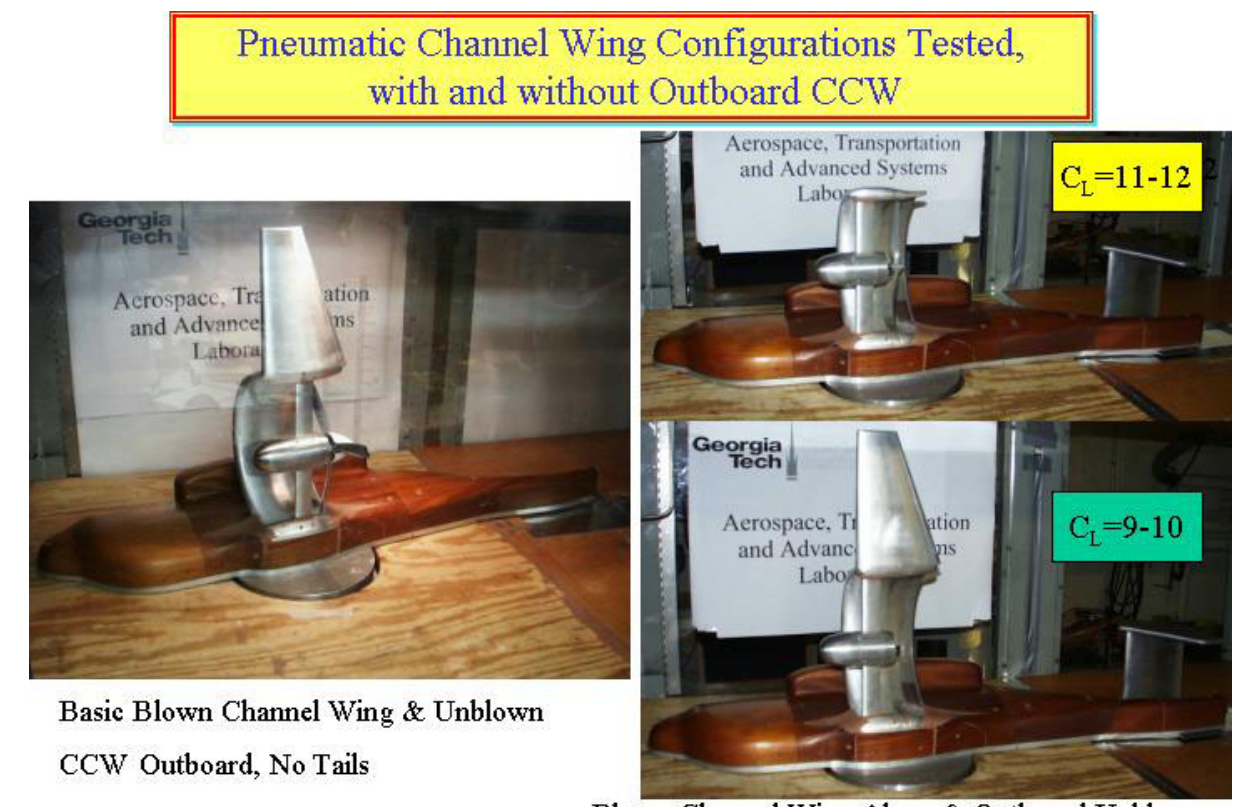

Blown Channel Wing Alone \& Outboard Unblown CCW, Both with H-Tail, Plus Outboard LE and TE CCW, New Tails, New Props

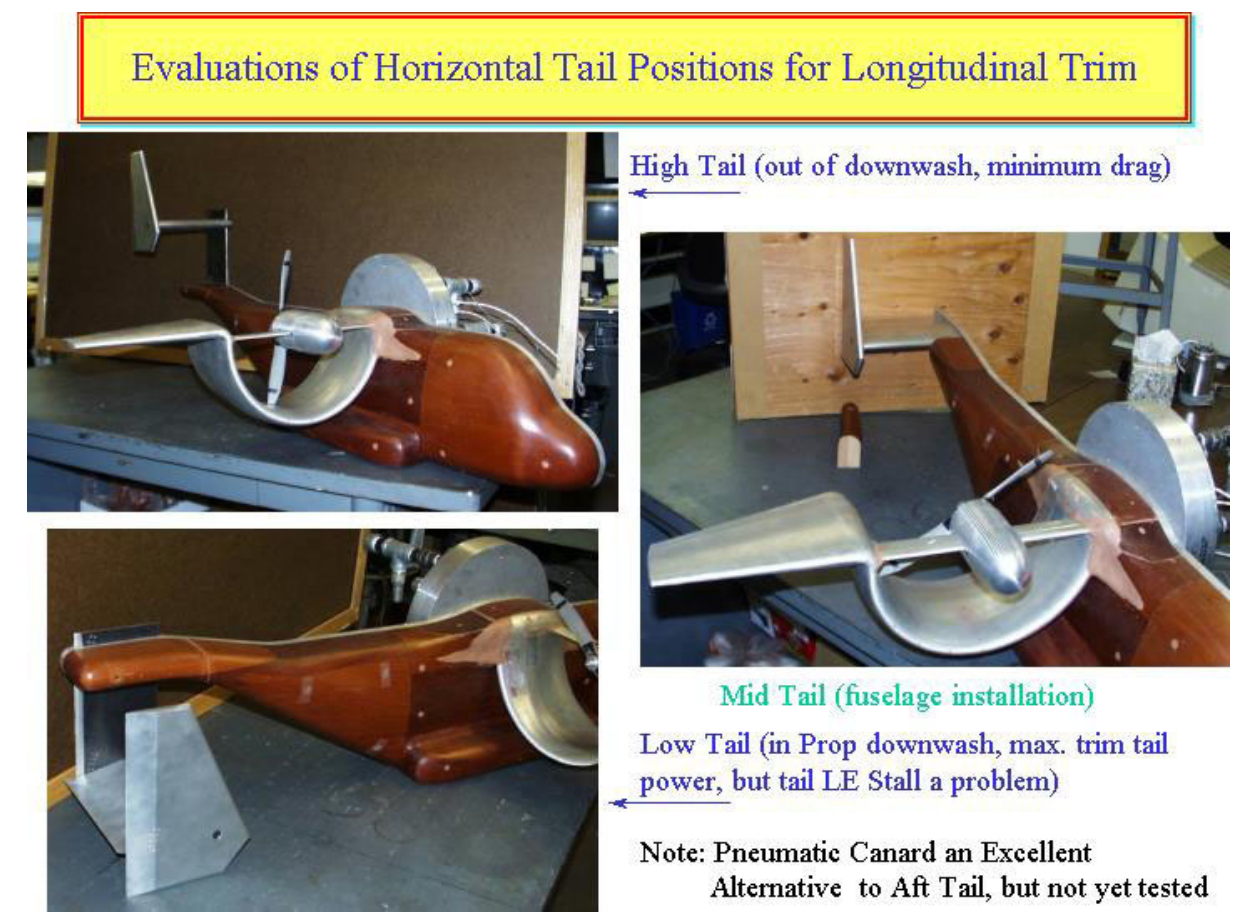


Pneumatic Channel Wing and Generic STOL Tilt Rotor Used in

Mission Analyses with STOL Takeoff and Landing Evaluations

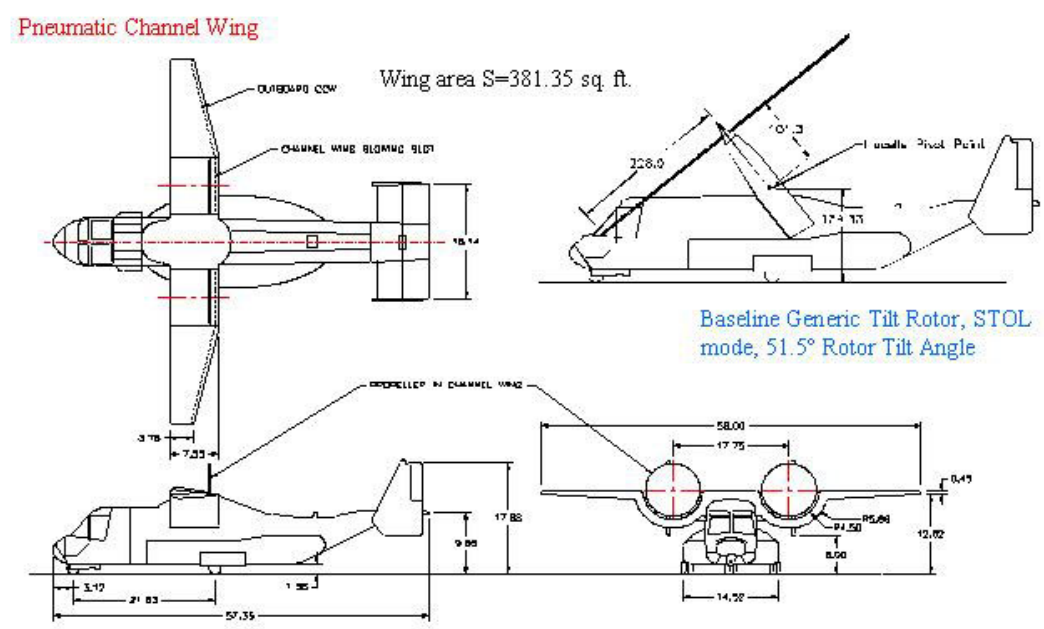

Predicted Pneumatic Channel Wing SuperSTOL Takeoff Performance 91.5 degrees, $h=3,000$ feet, Alpha $=10$

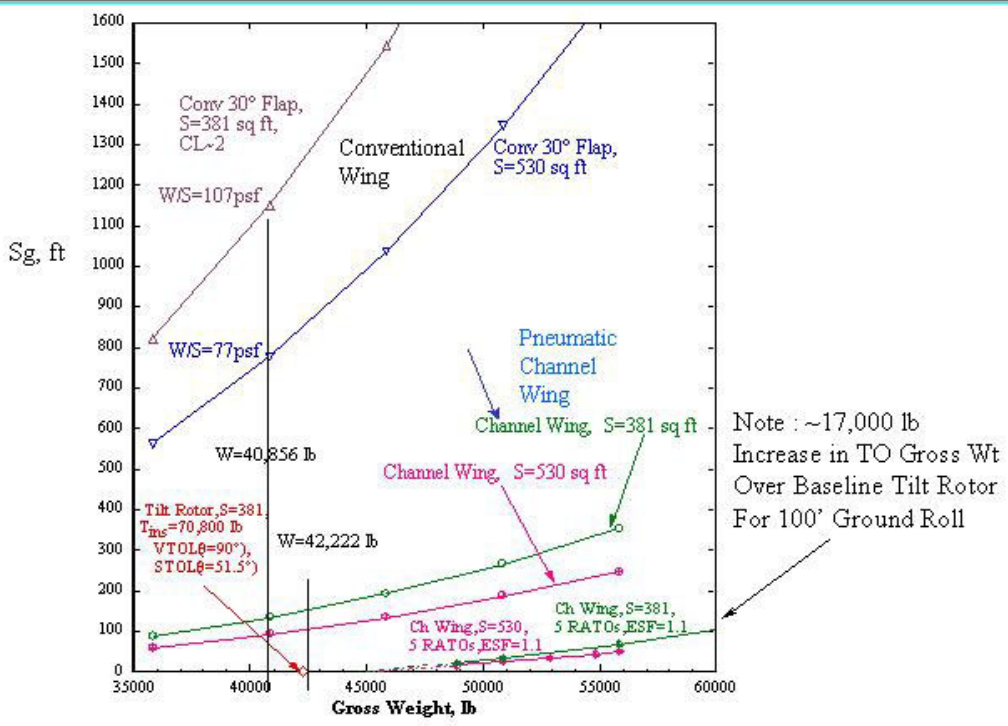




\section{SUMMARY \& CONCLUSIONS}

- Blown/Powered Tunnel \& Flight Investigations have confirmed CCW and/or the Pneumatic Channel Wing concepts for High Lift, Super STOL \& Overload capabilities

- Lift, Drag, all 3 Moments are all variable ( + or - ) by both $\mathrm{C}_{\mathrm{T}}$ and $\mathrm{C}_{\mu}$, and without moving elements More or Less $C_{L}, C_{D}$, and $C_{M}$ are available as required by Pilot or control system

- For Lift Augmentation and SuperSTOL, $\mathrm{C}_{\mu}$ more effective than $\mathrm{C}_{\mathrm{T}}$; High $\alpha$ Not Needed

- No Moving Parts are necessary for Blowing Benefits: Weight reduction

- $\mathrm{C}_{\mathrm{T}}$ can be converted to Thrust Recovery, $\mathrm{C}_{\mathrm{D}}$ increase, or even Thrust Reversal

- Trim and Low-speed Control ALWAYS Need to be addressed for SuperSTOL aireraft

- Wind-Tunnel and Flight-Test Data lead to significant Super STOL or VSTOL benefits, advantages and applications for Pneumatic Military, Commercial or Private Aireraft

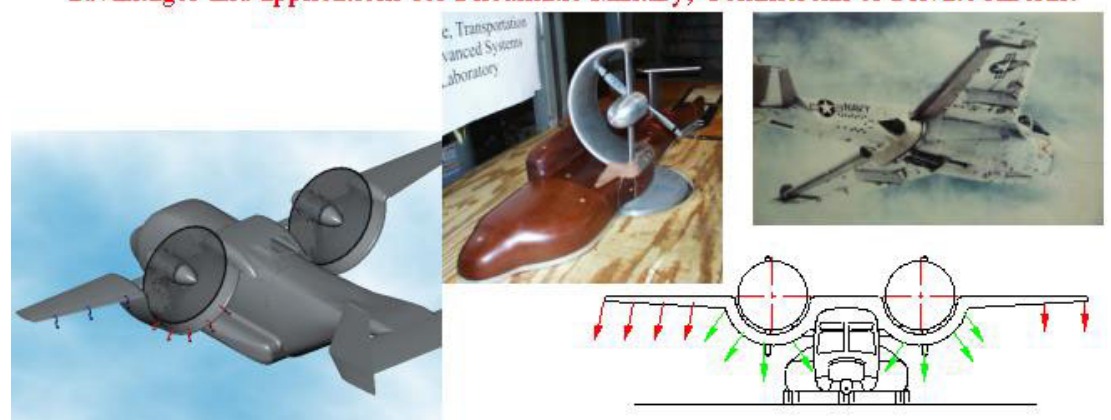

Projected Operational Benefits \& Advantages of Pneumatic Channel Wing

- Pneumatic/Propulsive High Lift Generated with Thrust Deflection and No Moving Parts:

$C_{L}=10-11$ or greater at $\alpha=10^{\circ}$; avoids high $\alpha$ operation, flow separation, loss of control

- Additional Lift from Outboard CCW surfaces: Yields high Overload Capability- No tilting rotors or tilting engines necessary!

- Non-moving Augmented Blown Control Surfaces yield Low-Speed Control: Pitch, Roll\&Yaw; Increased One-engine-out Control; High Response Rates from variable blowing

- Integrated Lift, Propulsion, and Control Systems yield Simplicity, Low Weight \& Inereased Performance; Systems Synergy yields inter-related multi-function components

- Pneumatic Channel Wing Provides Significant Powered Lift Without Rotor Tilt: Inereased Liftable Weight and Payload are possible with very short field length

- Super STOL and VSTOL Potential, with Possibility for Hover without Engine Tilt

- Channel Wing can "Hide" Propulsion System from Acoustic \& Infrared Detection

- No Download Impacting on Fixed Wing in Low speed or Hover; High DL = Higher Cruise V

- Signature Reduction; Payload Fraction Increase, Cost Reduction relative to Tilt Rotor

- These Benefits should be Quantified and Confirmed in Future research
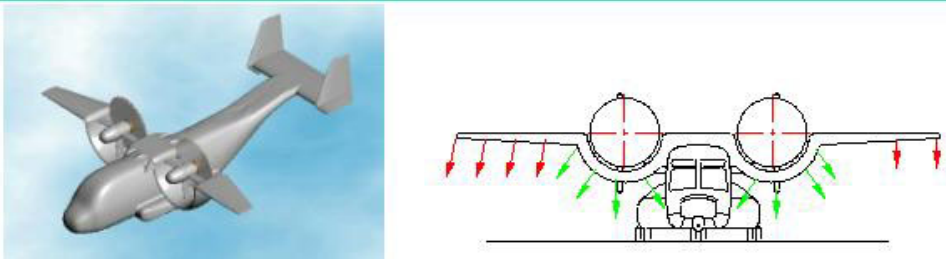


\section{Recommendations for Advanced Pneumatic Aircraft}

- Continue Analytical \& Experimental Development of 2-Engine Pneumatic Channel Wing Aireraft as SuperSTOL or V/STOL transport

- Analytically \& Experimentally Develop a 4-Engine Pneumatic Aircraft as an Advanced Transport with SuperSTOL or V/STOL and Overload capabilities (turboprop or jet driven)

- Develop CCW on a Pneumatic Fighter/Attack Aircraft with SuperSTOL and Overload Potential plus High Maneuverability

- Develop a CCW-only STOL Transport with Gross-Weight-

Overload capability on unprepared runways (Runway Independent Aircraft)

- Apply to Personal Air Vehicles and/or ESTOL vehicles for Small- or No-Runway Operation

Georgia Tech Research Institute and NASA Langley Research Center can help!! $\sim 36+$ years pneumatic technology development \& expertise; unique test facilities;

flight-test experience; related analytical capabilities and programs; and the

Enthusiasm to develop and employ this technology on future advanced aircraft 
Backup Slides

Custer Channel Wing, CCW-5, Flown in Powered-Lift Flight in Early 1960's

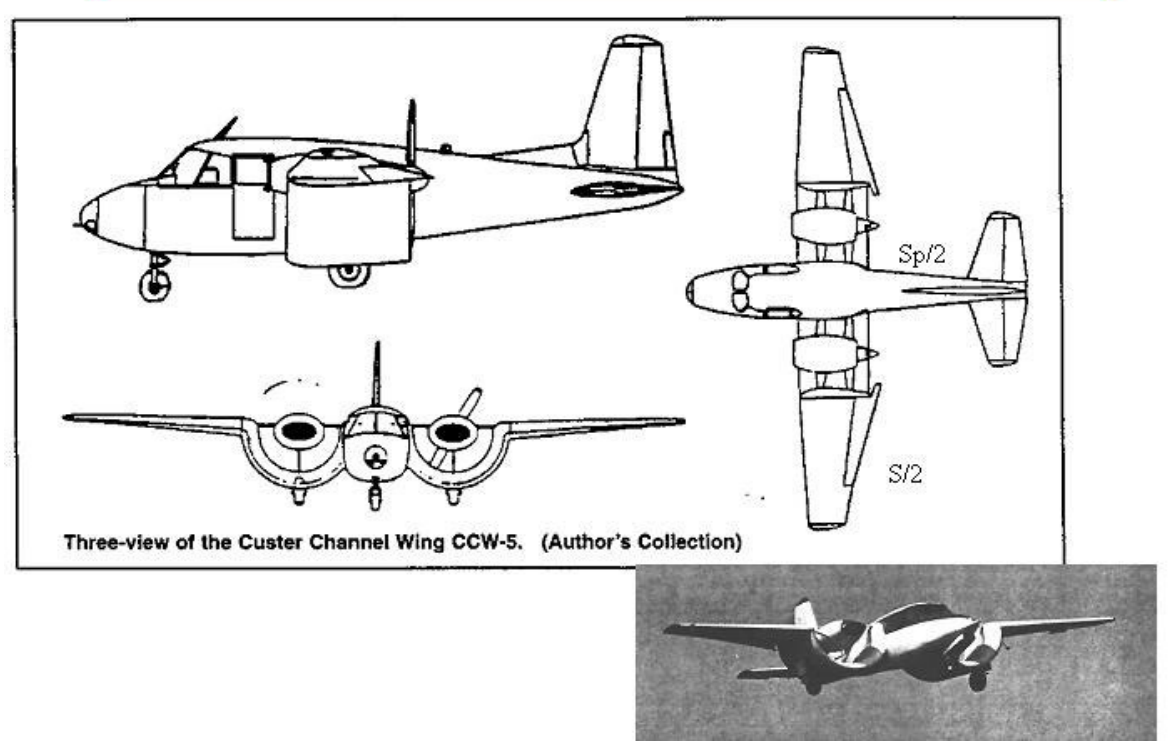


Channel Wing Model with Variable Nacelle Locations, to

Determine Effect of Prop Position on Flow Entrainment

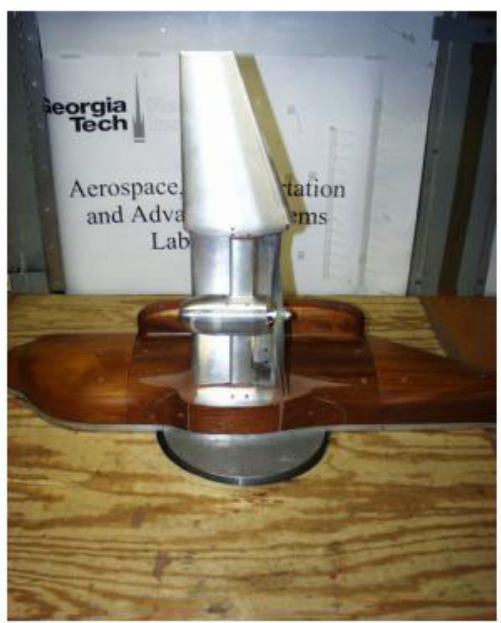

Channel Wing Configuration with Aft Prop/Nacelle Location, $x / c=0.95$

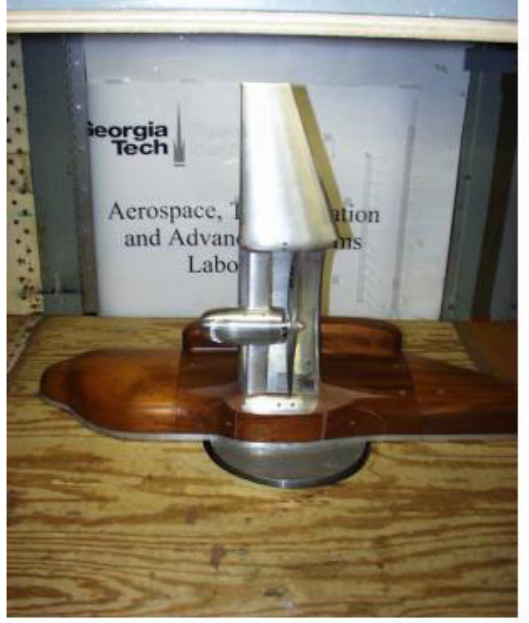

Channel Wing Configuration with

Forward Prop/Nacelle Location, $\mathrm{x} / \mathrm{c}=0.60$
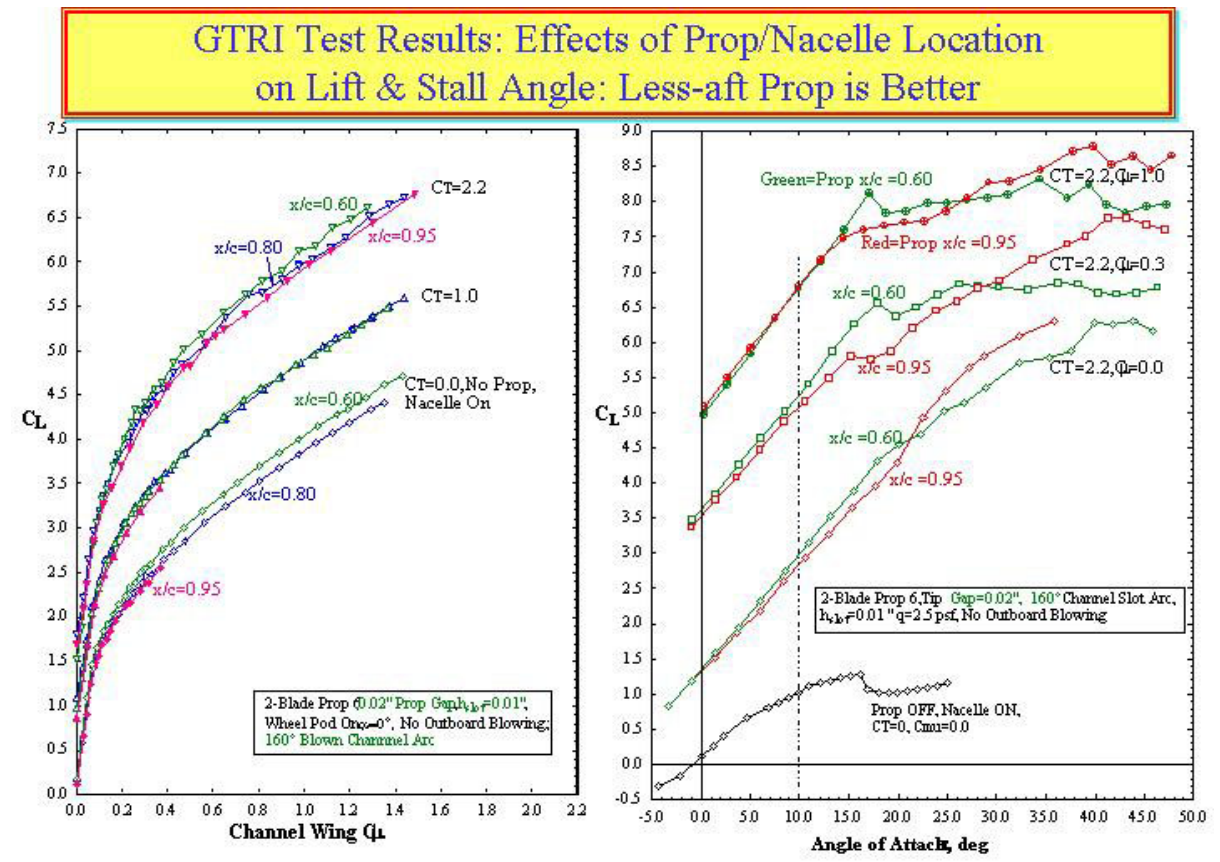


\section{Connection to Other Programs}

\section{Pneumatic channel wing provides enabling} technology for conceptual Personal Air Vehicles

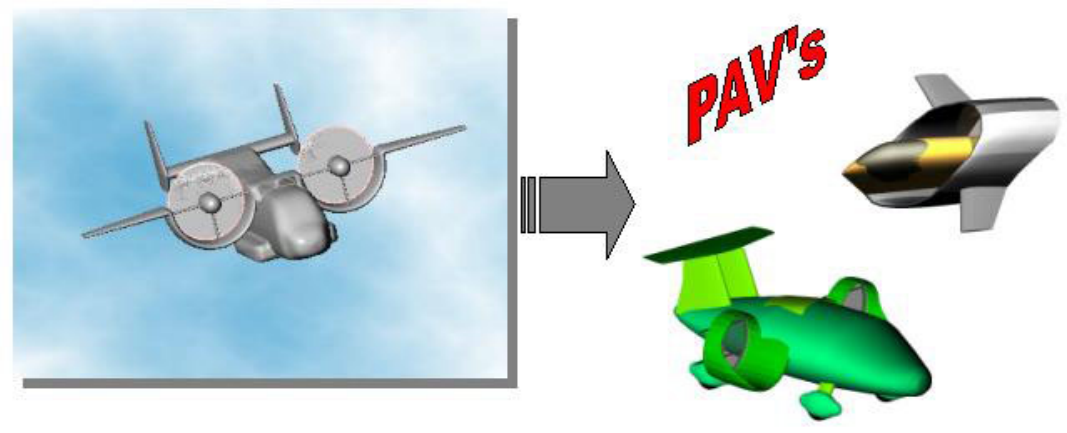

Comparison of Predicted \& Experimental Pneumatic Channel Wing Lift and Drag due to Blowing and Thrust Deflection, $\alpha=10^{\circ}$, No Outbd CCW

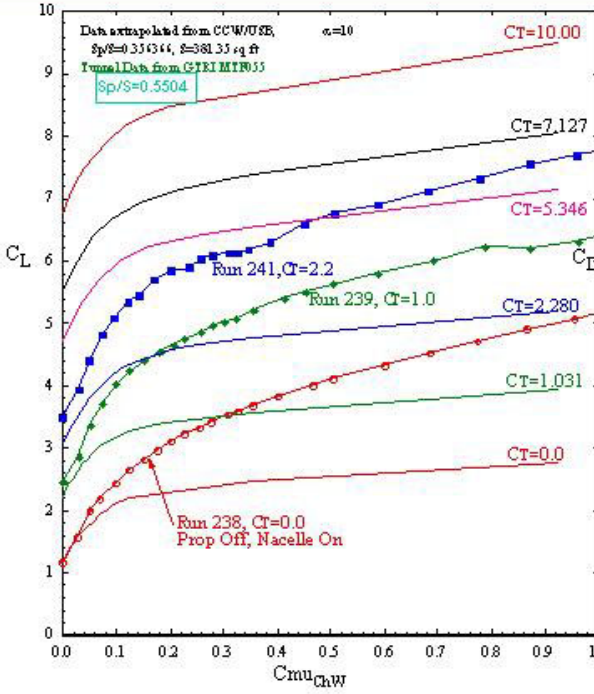

Lift Generated by Pneumatic Channel Wing At Higher $\mathrm{C}_{\mathrm{T}}, \mathrm{C}_{\mathrm{L}}>10$ \& Higher $\mathrm{T}$ Recovery Probable

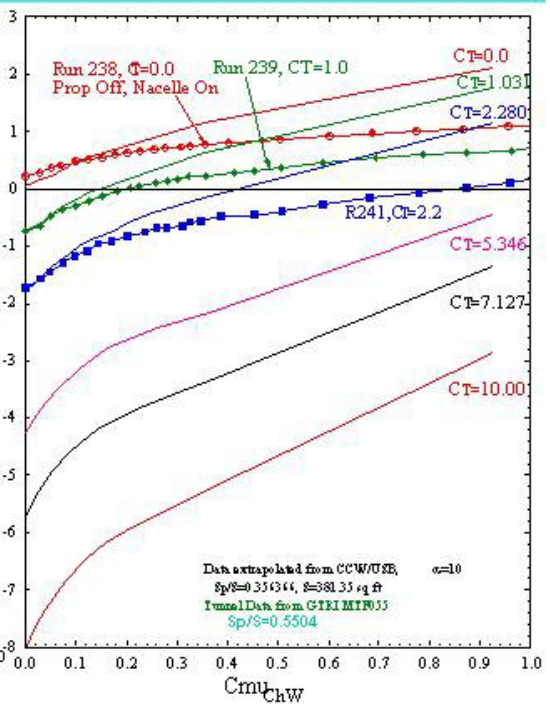

Drag (Including $\mathrm{C}_{\mathrm{T}}$ ) Generated by Pneumatic Channel Wing 

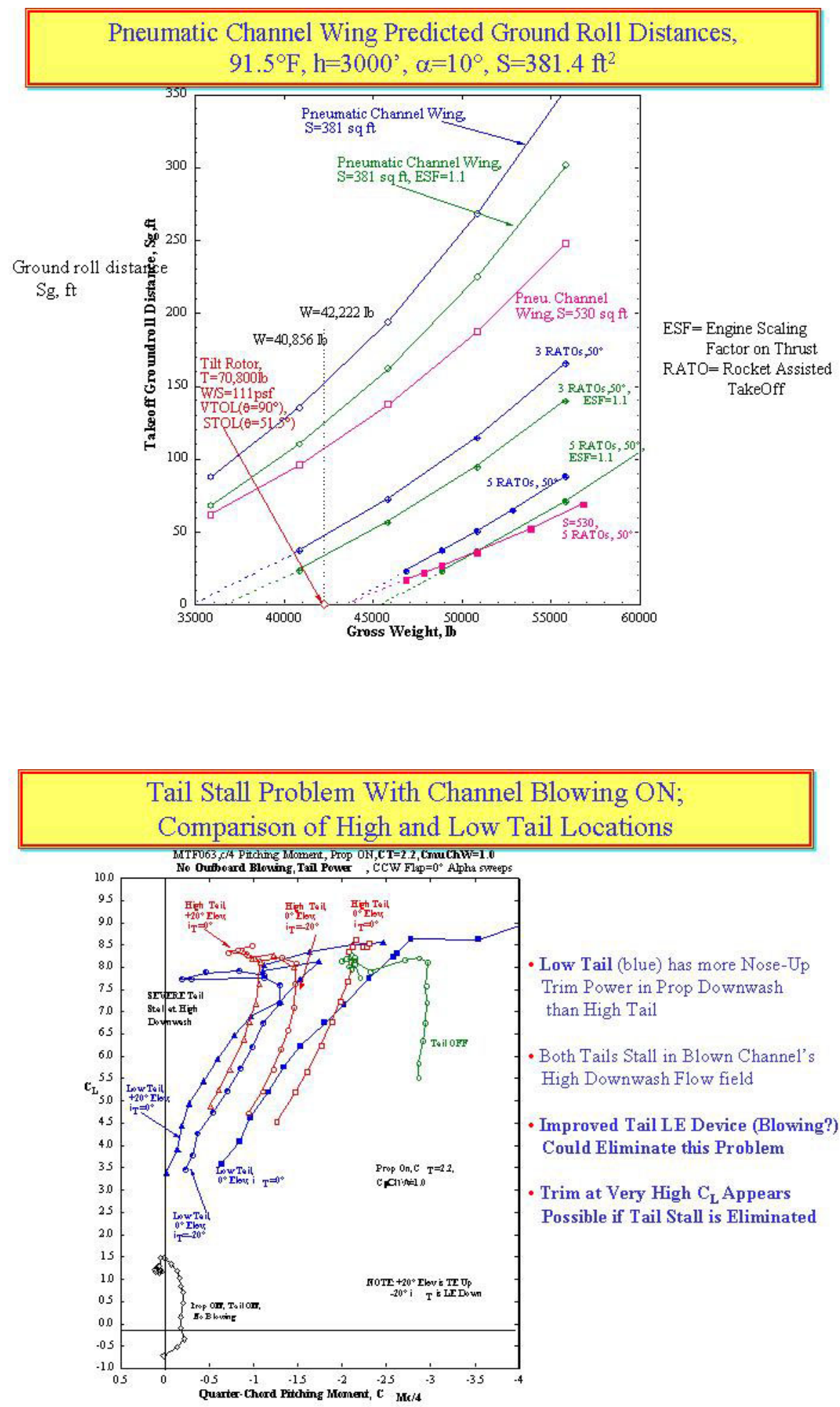